\title{
Sinú Sax Quartet: un laboratorio musical
}

Sinú sax quartet: A musical laboratory

Julio Castillo, sinusaxquartet@gmail.com

Universidad de Córdoba, Colombia

\section{Resumen}

En el presente artículo se listan algunas características de tipo formal y rítmico constituyentes de la música del Caribe Colombiano y algunas consideraciones de tipo melódico, armónico y funcional para la composición y elaboración de arreglos en el formato de cuarteto de saxofones.

Palabras claves: Música tradicional, patrones rítmicos, forma, rearmonización, rol.

\section{Abstract}

In this article, some characteristics of formal nature and constituents of rhythmic music in the Colombian Caribbean music are listed, and considerations of melodic, harmonic and functional type for the composition and preparation of arrangements in the format saxophone quartet are presented.

Keywords: Traditional music, rhythmic patterns, shape, re-harmonization, role. 


\section{Introducción}

La tradición, de hecho, actualiza y renueva el pasado desde el presente. La tradición, para mantenerse vigente, y no quedarse en un conjunto de anacrónicas antiguallas o costumbres fósiles y obsoletas, se modifica al compás de la sociedad, pues representa la continuidad cultural (Arévalo 2014).

La música en el Caribe colombiano, al igual que las mayorías de las músicas tradicionales, está íntimamente ligada a la danza y al baile. Vernia (2014) explica esta relación de la siguiente forma: «el ritmo es el responsable de organizar una pieza musical confiriendo movimiento a la música, y la mejor manera de aprender a seguir el ritmo es escuchar música interpretándola con el cuerpo a través del movimiento.» Sin embargo, este carácter «fiestero» no puede ser considerado como un impedimento para que sus elementos sean tomados como base para la elaboración de un nuevo producto orientado a formar un público que lo consuma desde una escucha crítica y valorativa, aunque esto no quiere decir que se deba dejar de lado las características que la hacen única y reconocible.

Por otro lado, la formación musical tradicional en el mundo tiene como génesis y objeto de desarrollo su propia música. Es decir, desde ella y para ella. El músico tradicional atesora lo que para él es significativo. Esta aseveración nos da pie, entonces, para formularnos la siguiente pregunta: ¿podemos formar músicos profesionales fundamentados en el diálogo entre lo tradicional y lo académico? Nuestra respuesta es si. Aunque somos conscientes de que una larga práctica de la oralidad y poca sistematización de las experiencias es un gran obstáculo para dar este paso determinante y ambicioso.

El anterior pensamiento nos trae al Sinú Sax Quartet, una propuesta que intenta consolidar, por un lado, un repertorio orientado a promover la práctica instrumental, desde la elaboración de materiales contextualizados basados en sonoridades contemporáneas. Inicialmente, sirve de complemento a la formación musical académica, con una marcada predominancia del estudio de la música clásica. Por otro lado, busca crear un público que disfrute de nuestra música fuera de su entorno original. Es así como en el presente artículo compartimos algunas experiencias de la manera cómo se han elaborado los arreglos y composiciones que hacen parte del repertorio de dicho ensamble instrumental planteando, desde una práctica muy particular, el tratamiento de algunos principios. Estos incluyen: las formas, algunos patrones rítmicos de la música del Caribe colombiano, la armonía, consideraciones melódicas, técnicas de re-armonización y el papel de los saxofones en los arreglos.

\section{$1 \quad$ El porqué del Sinú Sax Quartet}

Históricamente, el saxofón ha jugado un papel importante como medio expresivo en la configuración de la música del Caribe colombiano. Su importancia se remonta a mediados del siglo pasado en las orquestas de baile, formato inspirado, pero con algunas variaciones, en las big bands Americanas. Al respecto Wade (2000) documentó: «Para la década de los cuarenta ya estaban apareciendo porros, fandangos y cumbias, aun en las tandas del Hotel El Prado, donde estaba contratada la Emisora Atlántico Jazz Band» (p.111).

En tal virtud, maestros importantes del Caribe colombiano como Lucho Bermúdez, Pacho Galán, Antonio María Peñaloza y Simón Mendoza, entre otros, tomaron como base dicho formato para desarrollar su potencial creativo. En estas orquestas, el papel del saxofón generalmente, consistía en ser un instrumento acompañante necesario para los «background» y los «mambos» de los porros, cumbias y fandangos. También, se desempeñaba como instrumento solista, rol sobre el cual se edificó lo que se podría denominar hoy día como el sonido del «Saxofón costeño» y del cual citamos algunos 
de sus representantes: José del Carmen «Cheito» Guerra, Antolín Lenes, Alex Acosta «Muñecón», Carlos Piña y Justo Almario, entre otros.

Cambiando de escenario y adentrándonos en las llanuras del Caribe, en el ambiente rural del departamento de Córdoba, encontramos una resistencia histórica a la inclusión del saxofón en las bandas de viento de formato «Pelayero». En los músicos de la región ha permanecido el imaginario de que su sonido es débil y, por tal razón, ocultado por la masa sonora producida por dicho conjunto instrumental. Es necesario tener en cuenta que los escenarios más frecuentados por estas bandas son las corralejas y fandangos, eventos realizados al aire libre sin elementos acústicos que permitan un trabajo dinámico equilibrado, Amador (1997) recoge esta percepción y afirma que «el saxofón es como un perro faldero ante perros cazadores como lo son los clarinetes».

Sin embargo, la percepción en el departamento hacia el instrumento denotó un cambio a partir de la apertura del programa de licenciatura en Educación Artística con Énfasis en Música de la Universidad de Córdoba, en el año 2000. En su plan de estudios este programa contemplaba la formación instrumental en Saxofón, lo cual permitió la aparición de nuevos intérpretes con una estructuración académica sólida y con los cuales se pudo consolidar y dar inicio al proyecto Sinú Sax Quartet, motivados, entre otros, por los siguientes objetivos: 1) Divulgar, a nivel nacional e internacional, la música de la región Caribe colombiana, 2) Fomentar el cuarteto de saxofones como un formato importante en el movimiento musical del Caribe colombiano, 3) Producir materiales para la formación académica de los estudiantes e intérpretes de saxofón con base en la música tradicional y 4) Posicionar la música de la región como una expresión digna de escucharse y apreciarse en escenarios distintos a los de las festividades).

A continuación, listaremos algunos elementos que se tuvieron en cuenta durante el proceso de elaboración del repertorio, constituido por el diálogo entre dos universos sonoros. Por un lado, la fuerza rítmico-melódica del Caribe y sus formas y, por el otro, las técnicas de rearmonización documentadas en textos de orientación jazzística, principalmente.

\section{Algunas formas y patrones rítmicos de la música del Caribe colombiano}

A pesar de existir un grueso número de formas regionales, en las cuales los compositores del Caribe enmarcan sus obras, debemos acotar que, por lo extenso de la temática, solo nos referiremos a algunas de ellas, en especial a las desarrolladas en el repertorio del cuarteto. En este punto es importante decir que no existe una fórmula única, ya que cada compositor o arreglista determina sus variaciones. Sin embargo, en todos los casos, su lógica opera con base en partes contrastantes.

a El porro y la cumbia: Estos son los géneros de mayor representatividad en la historia musical de la región. Si bien es cierto que el Vallenato es la música caribeña de mayor consumo en la actualidad, este es un fenómeno comercial reciente que data de los años cuarenta (Gilard citado en Wade, p. 82). Sin embargo, el Porro y la Cumbia se constituyeron como la base del repertorio de las orquestas de baile de otrora, heredándonos un importante número de obras que, a pesar del tiempo, han perdurado en el imaginario costeño y colombiano. Estos, por lo general, comparten momentos similares pero su estructura obedece casi siempre a una misma lógica. A continuación ilustramos la más generalizada, citando la obra San Carlos, en donde se ilustra las secciones contrastantes en las cuales se basa la mayoría de música tradicional y popular del Caribe colombiano. 
Castillo
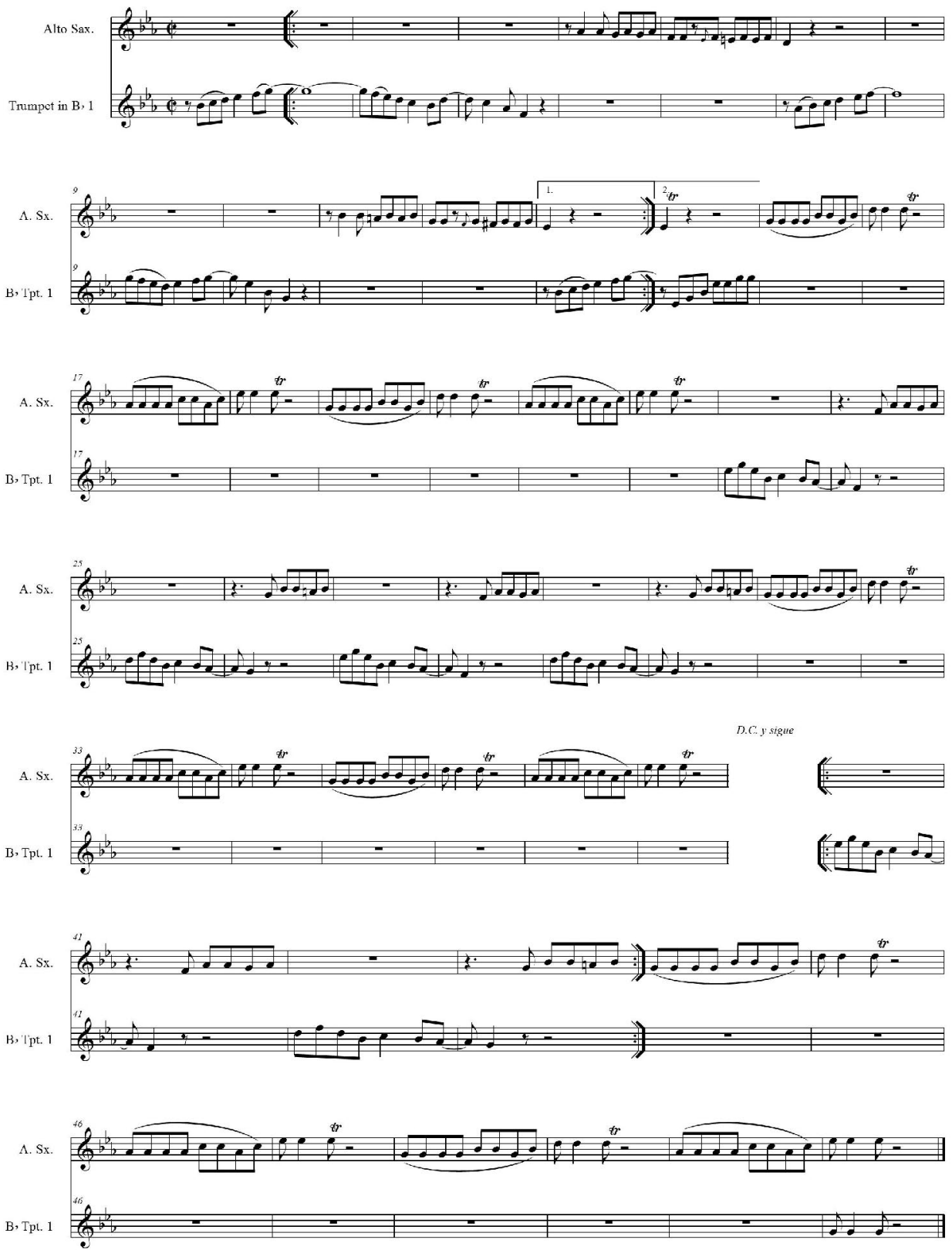

Figura 1. Estructura más generalizada: A - Puente - B. San Carlos (Porro) Autor: Eliseo García (1914-1968)

b Porro Palayero: Este es el género de mayor representatividad de las bandas de viento de la región del Sinú. Posee como característica principal, heredada de los cantos africanos, la alternancia entre un solista y un estribillo. A continuación, su forma más trabajada, aun cuando se le hayan incorporado nuevas variaciones en su evolución: 

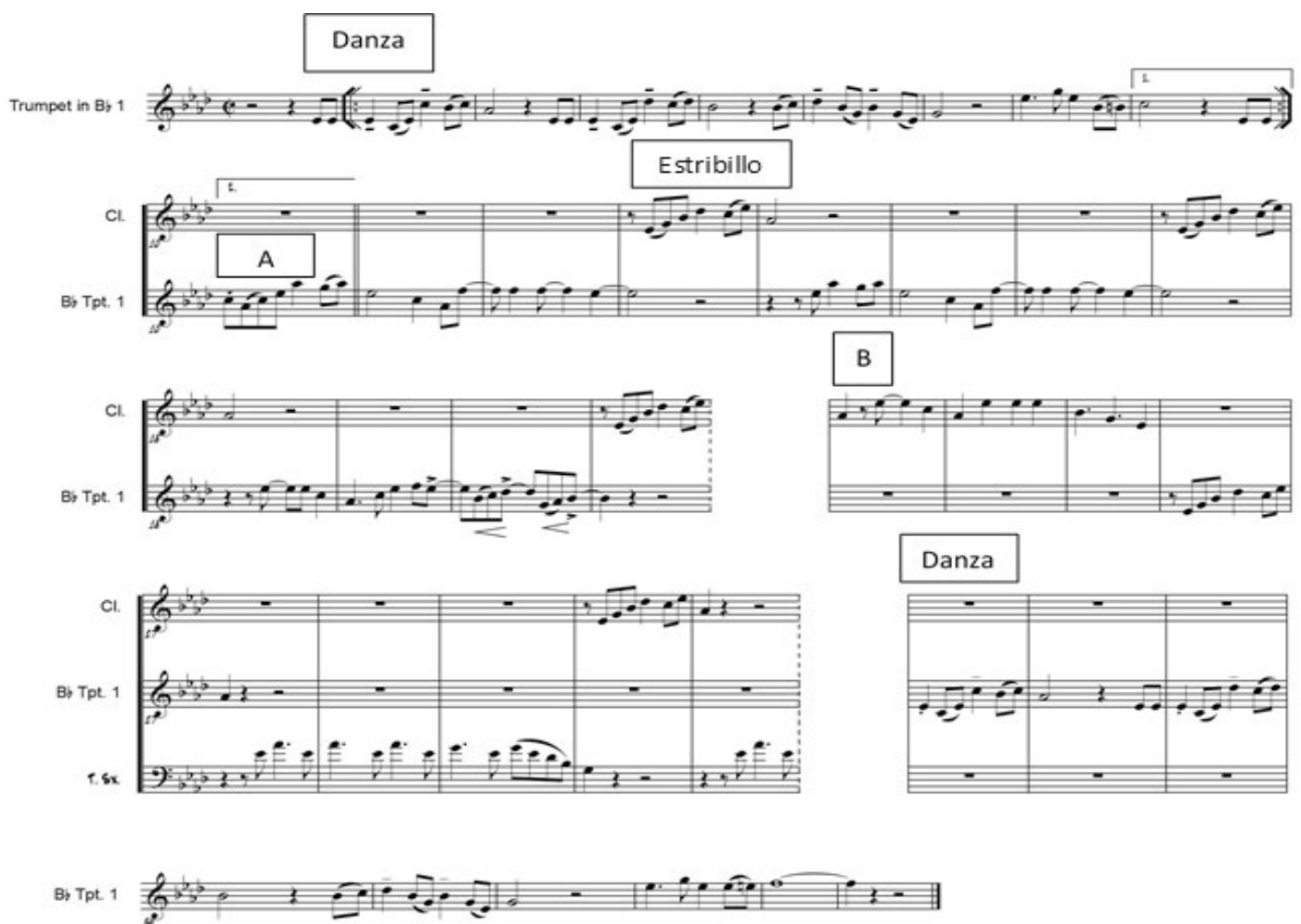

Figura 2. Estructura del Porro Palitiao: Danza-A-B-Danza. Río Sinú (Porro palitiao) Composición colectiva Banda 19 de marzo de Laguneta, 1986

c Patrones rítmicos: En este punto es relevante señalar que existe un elemento cohesionador en los ritmos que conforman la música del Caribe colombiano. Este componente es el contratiempo: unidad característica e importante que se encuentra inmerso en una cantidad representativa de patrones, interpretado, no solo por instrumentos de percusión, sino también, por instrumentos melódicos y armónicos que cumplen el rol de acompañantes. Por consiguiente, listaremos algunos ritmos trabajados en el repertorio del Sinú Sax Quartet donde se evidencia dicho elemento e ilustraremos, también, la manera cómo fueron abordados cada uno de los patrones rítmicos que lo contienen. A contiuación ilustarmos el patrón rítmico de la cumbia; caracterizado principalmente por los acentos en contratiempo.

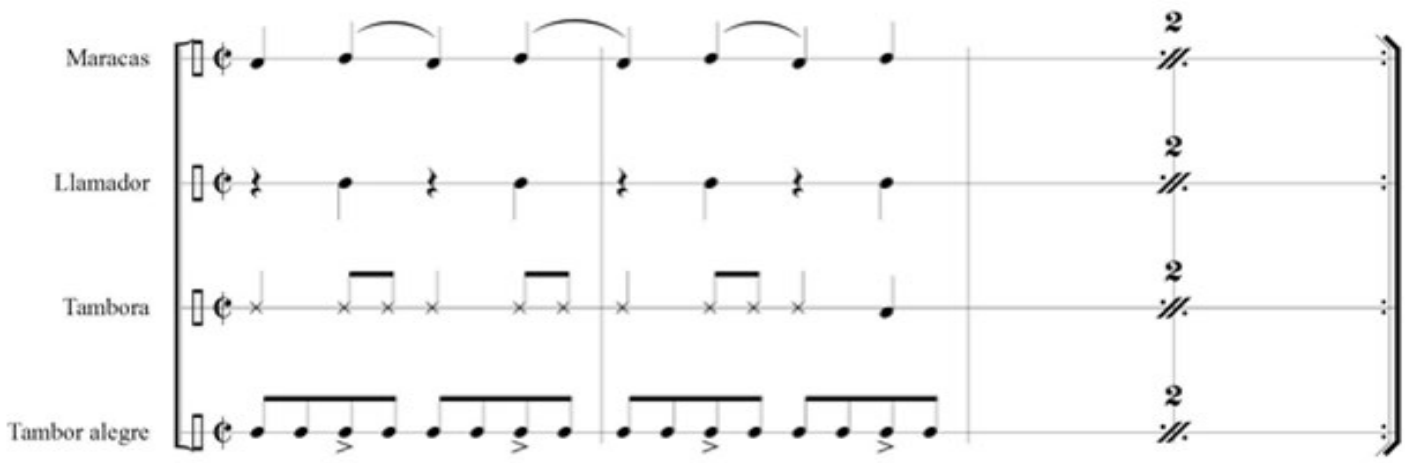

Figura 3. Patrón rítmico de la Cumbia 
En el siguiente fragmento de la introducción del arreglo de La Piragua (José Barros, 1915-2007), encontramos, de manera literal, los patrones tanto del llamador, interpretado por los saxofones: soprano; alto y tenor, como el de la tambora tocada por el saxofón barítono, del cual conserva solamente el golpe que se da en el parche:

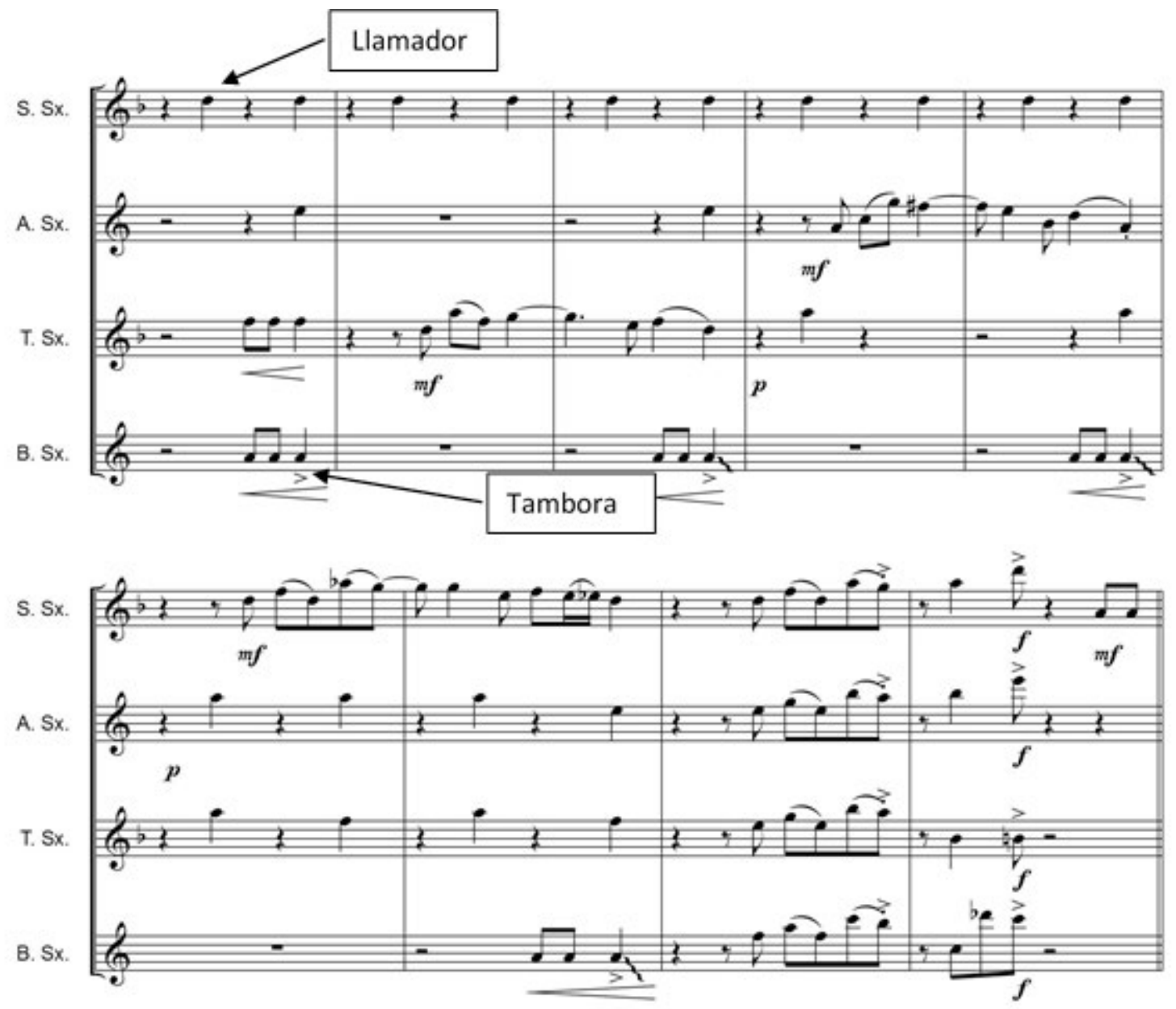

Figura 4. Fragmento de la Piragua 1

De igual forma, en el mismo arreglo, este patrón rítmico es desarrollado en todos los saxofones, de manera alternada, no solo como contratiempo sino como síncopas que soportan la rearmonización, dando así variedad al ritmo: 

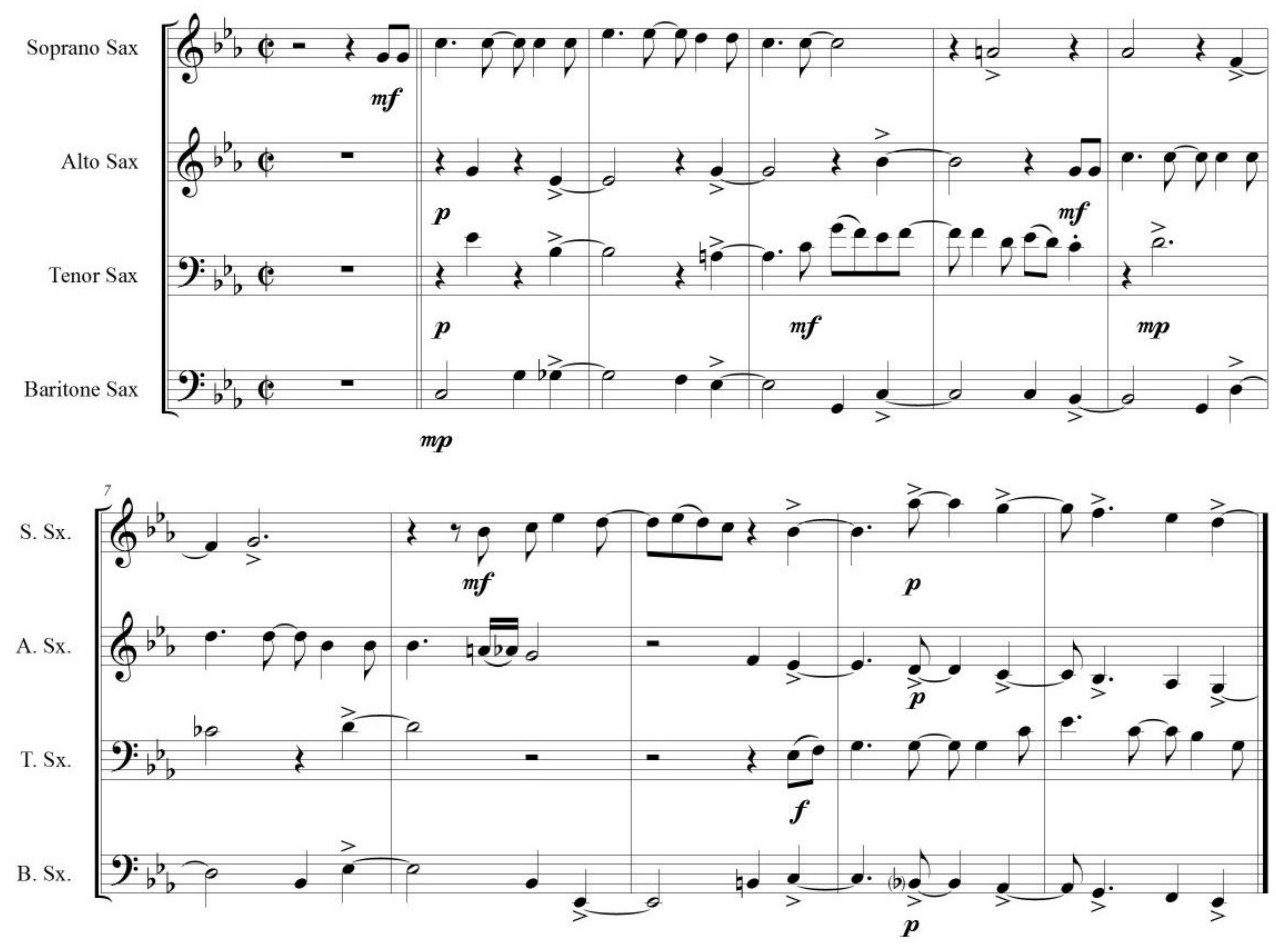

Figura 5. Fragmento de la Piragua 2

Los siguientes son patrones rítmicos del porro cultivados en el formato de banda Pelayera:

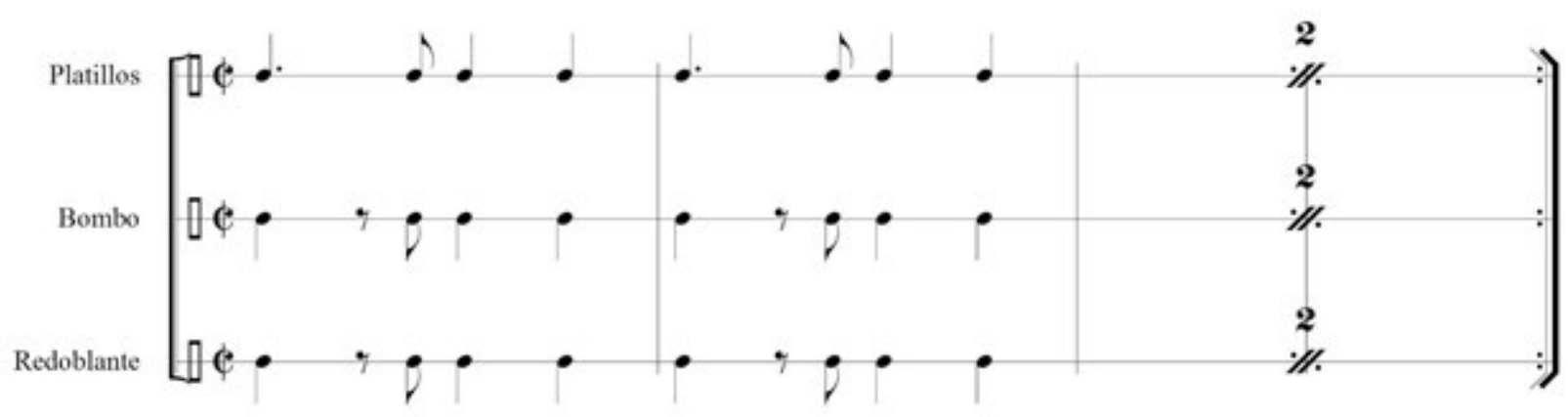

Figura 6. Patrones rítmicos de la danza del Porro palitiao

En el siguiente fragmento del porro "Río Sinú" (Composición colectiva banda 19 de marzo de Laguneta, 1987) ejemplificamos lo forma como se empleó este patrón rítmico: 

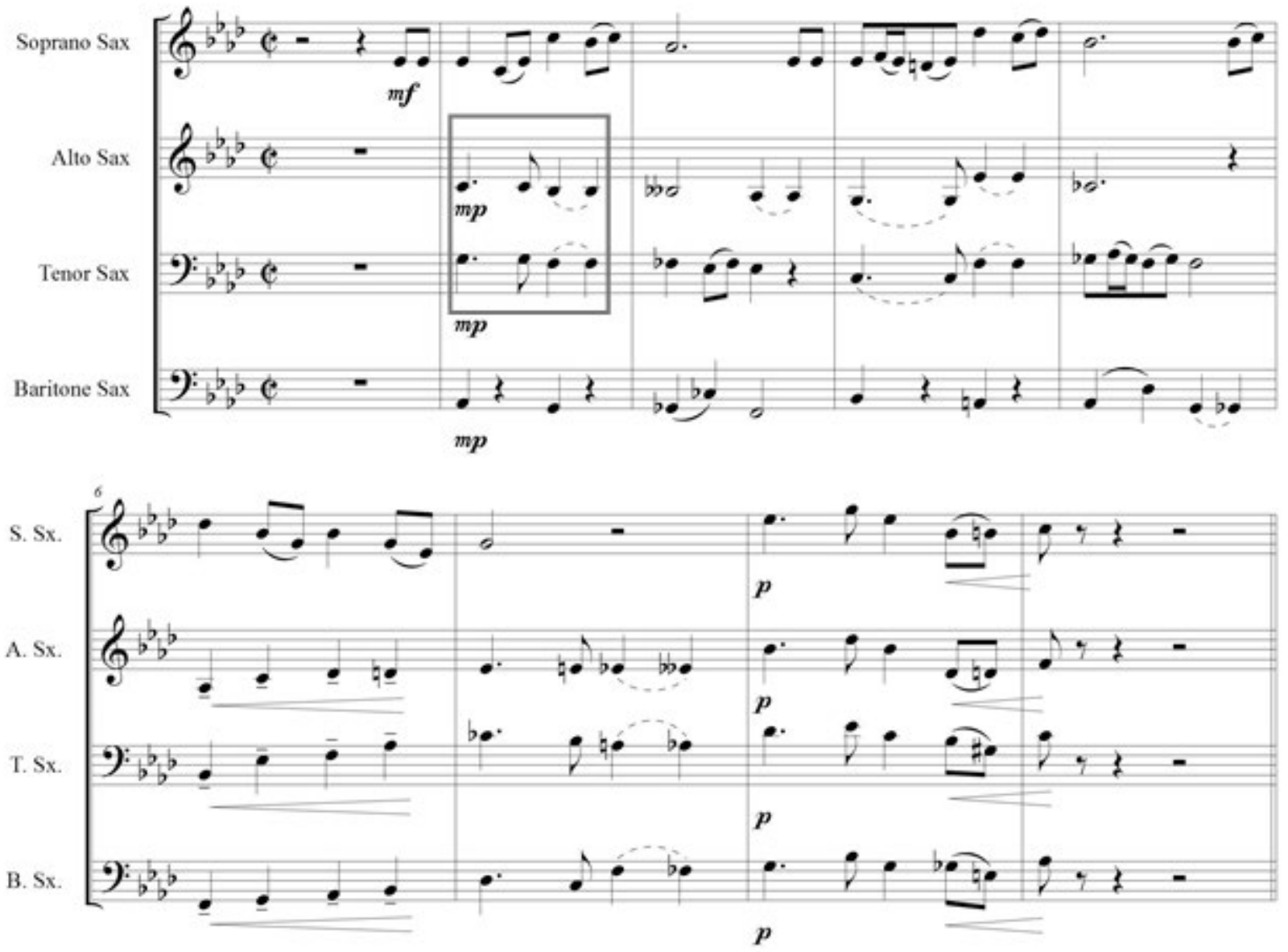

Figura 7. Ejemplo de la utilización de los patrones de la danza como soporte ritmico-armónico en el porro Río Sinú

Parte A, común a las diferentes clases de porro:

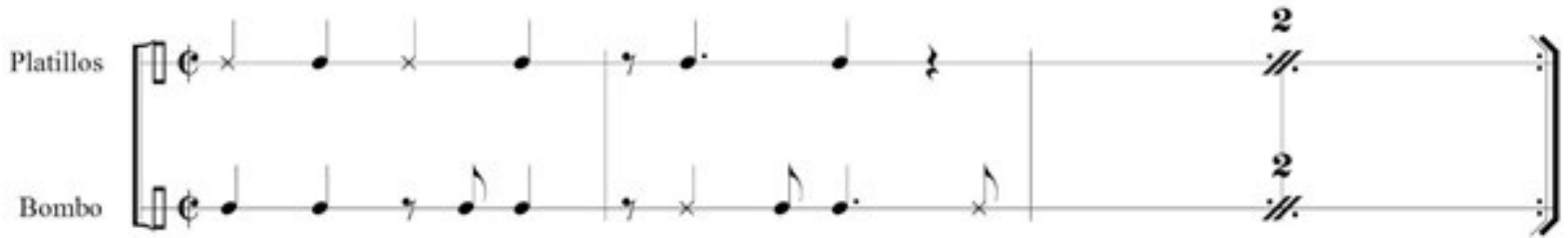

Figura 8. Patrones ritmicos que constituyen la parte A de los porros

Podemos notar, en los fragmentos 9 y 10 de «Carmen de Bolívar» (Luis Bermúdez 1912-1994), que el patrón está dividido entre el saxofón barítono y el saxofón tenor con algunas variaciones pero conservando los sonidos y acentos que lo definen. 

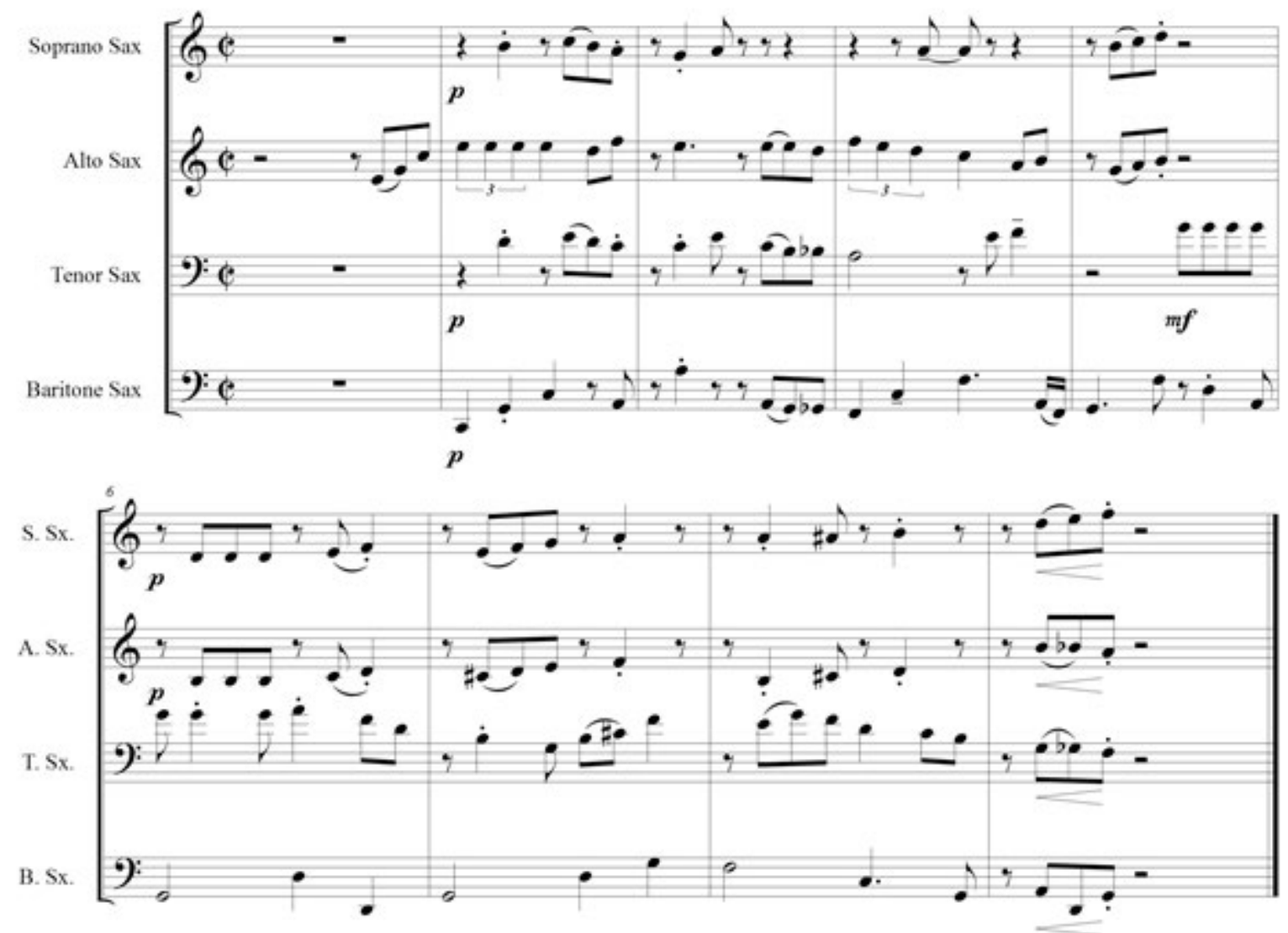

Figura 9. Ejemplo de los Patrones rítmicos que conforman la parte A en «Carmen de Bolívar»

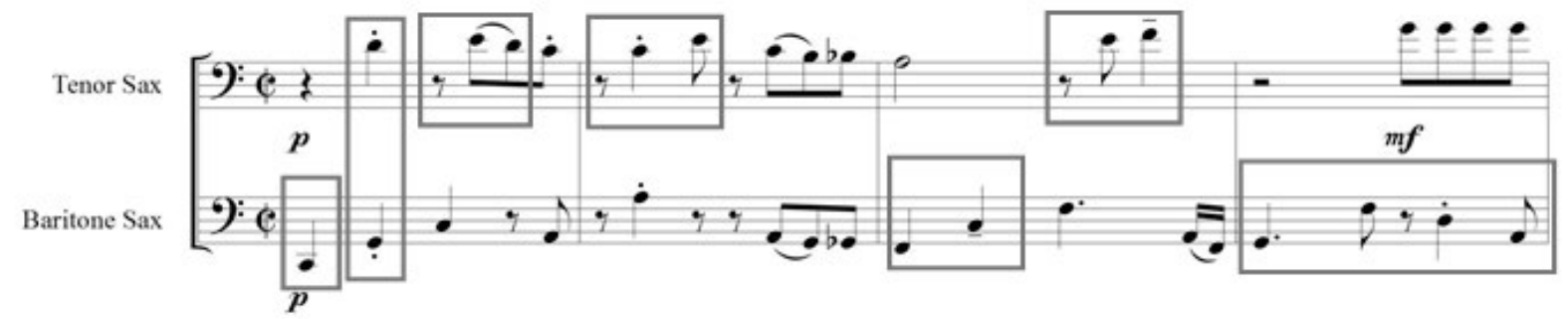

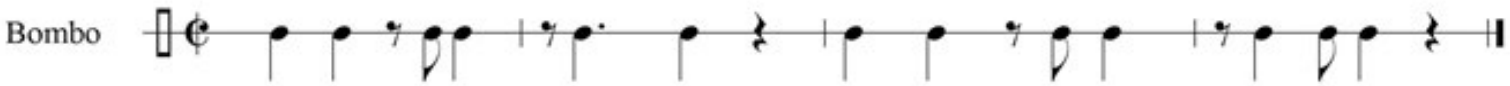

Figura 10. Ejemplo detallado de los Patrones rítmicos que conforman la parte A en «Carmen de Bolívar» y su distribución en los saxofones tenor y baritono 
Otro de los géneros ejecutados por Sinú Sax Quartet es el fandango.

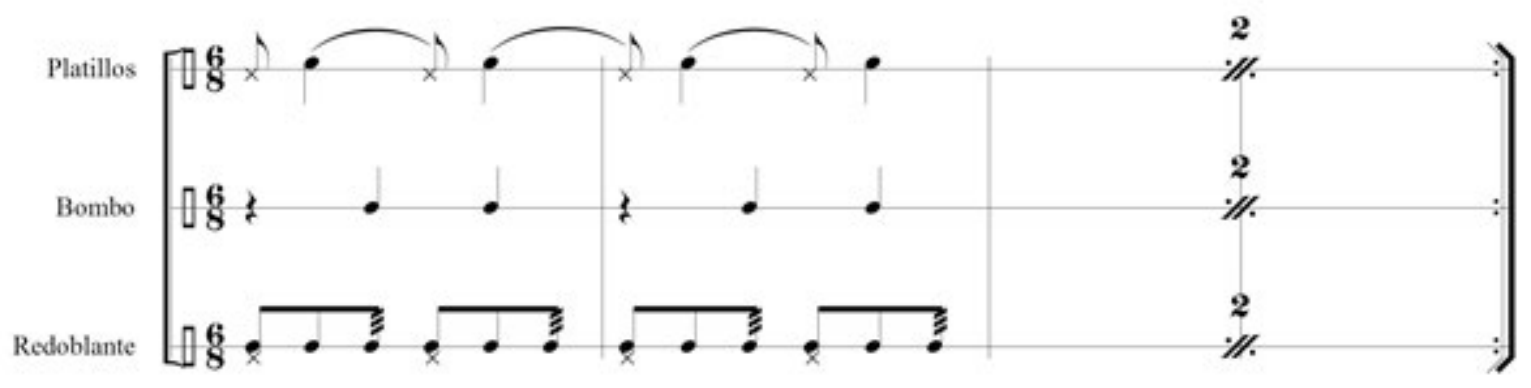

Figura 11. Patrones rítmicos que conforman el Fandango

En el siguiente fragmento del Fandango «La mala palabra» (Tradicional del Sinú) ilustramos como el patrón rítmico se divide, igualmente, entre el saxofón barítono y el saxofón tenor. Su síntesis consiste en tomar el primer golpe del redoblante, o sea, la primera corchea, y los golpes, que se encuentran en la tercera y quinta corchea, del bombo, determinando en gran medida el juego rítmico del fandango:
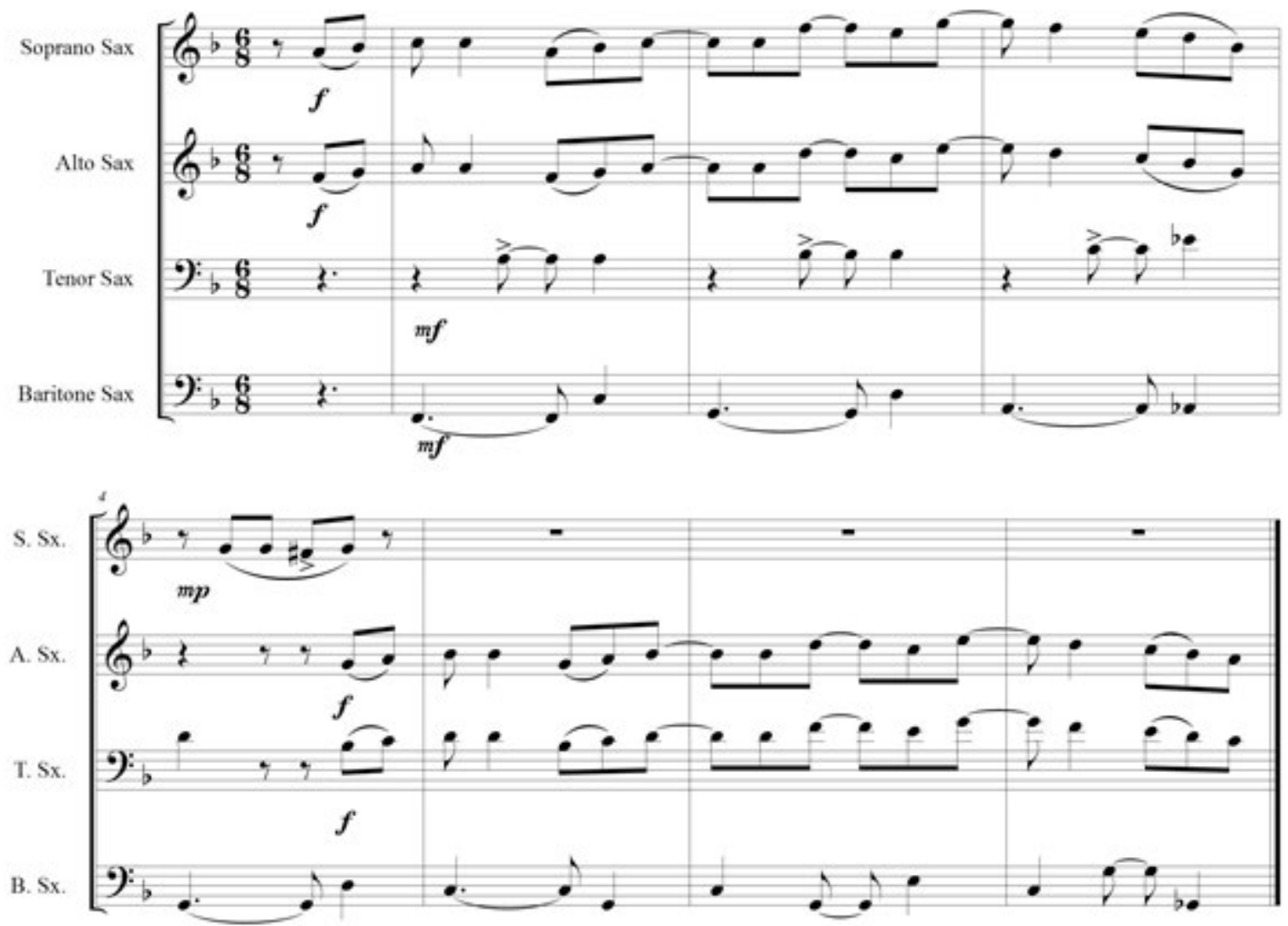

Figura 12. Patrones ritmicos que conforman el Fandango sintetizados entre los saxofones tenor y baritono 


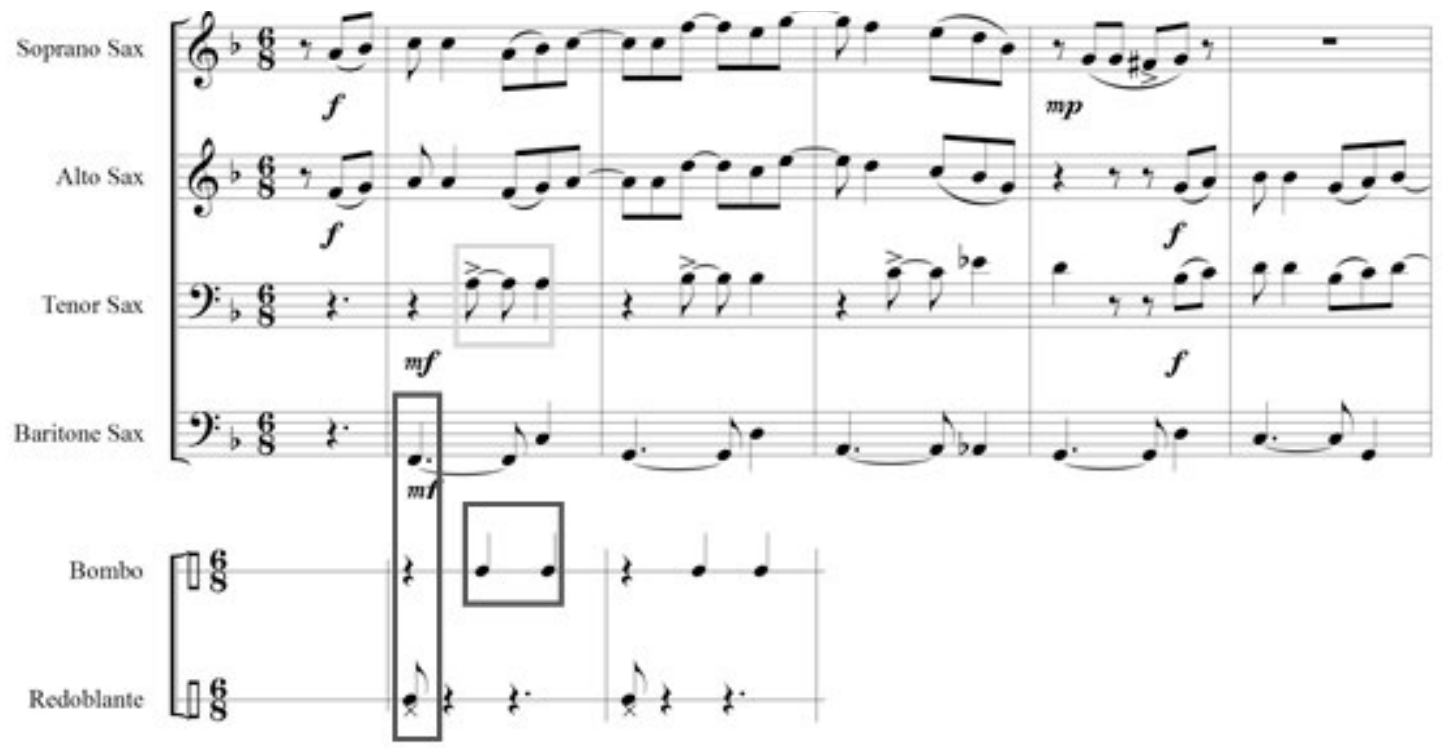

Figura 13. Síntesis detallada de los Patrones rítmicos del fandango

\section{La armonía, principal medio para la transformación:}

Si la música del Caribe colombiano se caracteriza por su vitalidad rítmica y melódica, debemos decir, también, que la armonía es su aspecto menos evolucionado y explorado. Su uso se ha limitado, en gran medida, en el establecimiento de las funciones tonales principales: tónica y dominante y, en menor proporción, la subdominante. Es por la razones expuestas que consideramos la reelaboración en el aspecto armónico como la contraparte necesaria para lograr el equilibrio ante tal fuerza rítmica y melódica de dicha música.

a Recomendaciones iniciales: a continuación se definirán e ilustrarán algunos aspectos, tanto melódicos como armónicos, tenidos en cuenta en la aplicación de las técnicas que permitieron el desarrollo de la armonía en los arreglos del Sinú Sax Quartet. Los sonidos guías y su apropiada conducción son un medio importante para lograr que la armonía se enlace de manera lógica. Estos sonidos determinan, como primera medida, el modo del acorde y, en segunda instancia, la función que está cumpliendo dicho acorde en una secuencia armónica determinada. En el siguiente enlace IIm7 V7 I Maj7 las ilustraremos:

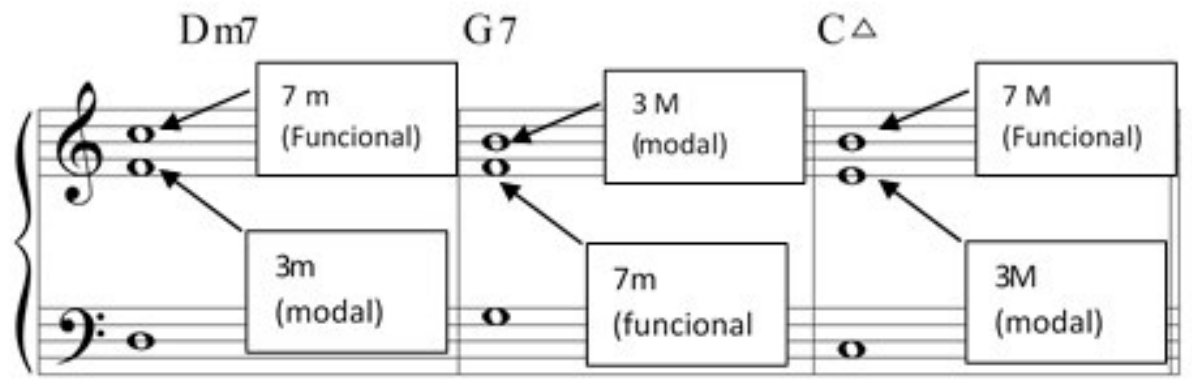

Figura 14. Ejemplo de las notas guías de los acordes 
Por otro lado, la fluidez de la conducción de estos sonidos está estrictamente determinada por el movimiento de la fundamental. Si este se da por movimiento de quinta, la séptima resuelve a la tercera y la tercera a la séptima:

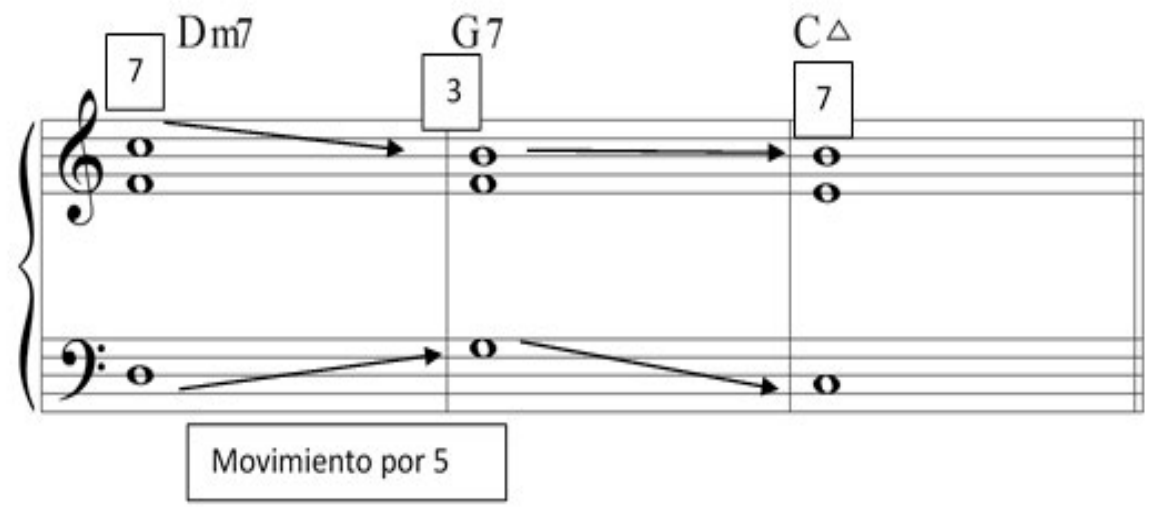
$\mathrm{Dm} 7$
G7
$\mathrm{C} \Delta$

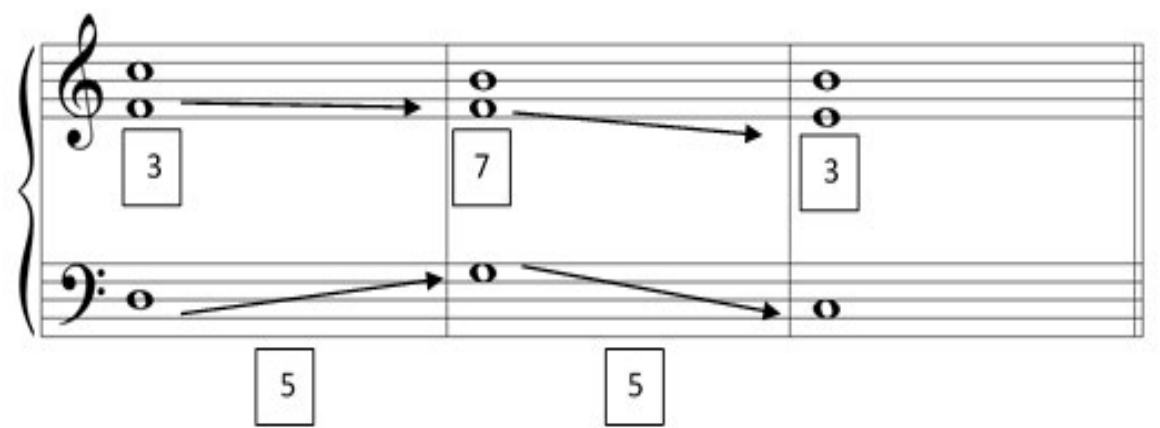

Figura 15. Resoluciones de las las notas guías de los acordes determinadas por el movimiento de quinta del bajo

Ahora bien, si el Movimiento de la fundamental es distinto al intervalo de Quinta Justa, entonces, las notas guías conservan su posición:

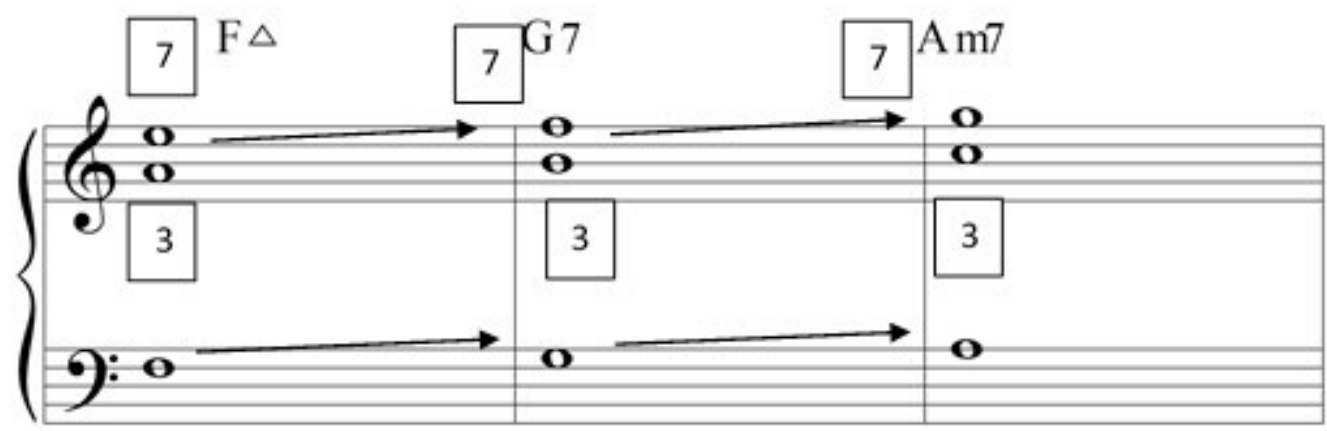

Figura 16. Resoluciones de las notas guías de los acordes determinadas por el movimiento, diferente al de quinta, del bajo 
El siguiente fragmento es un claro ejemplo de la manera cómo se utilizó este recurso. Observamos que el saxofón barítono interpreta la fundamental de los acordes mientras que el saxofón tenor se encarga de las notas guías:
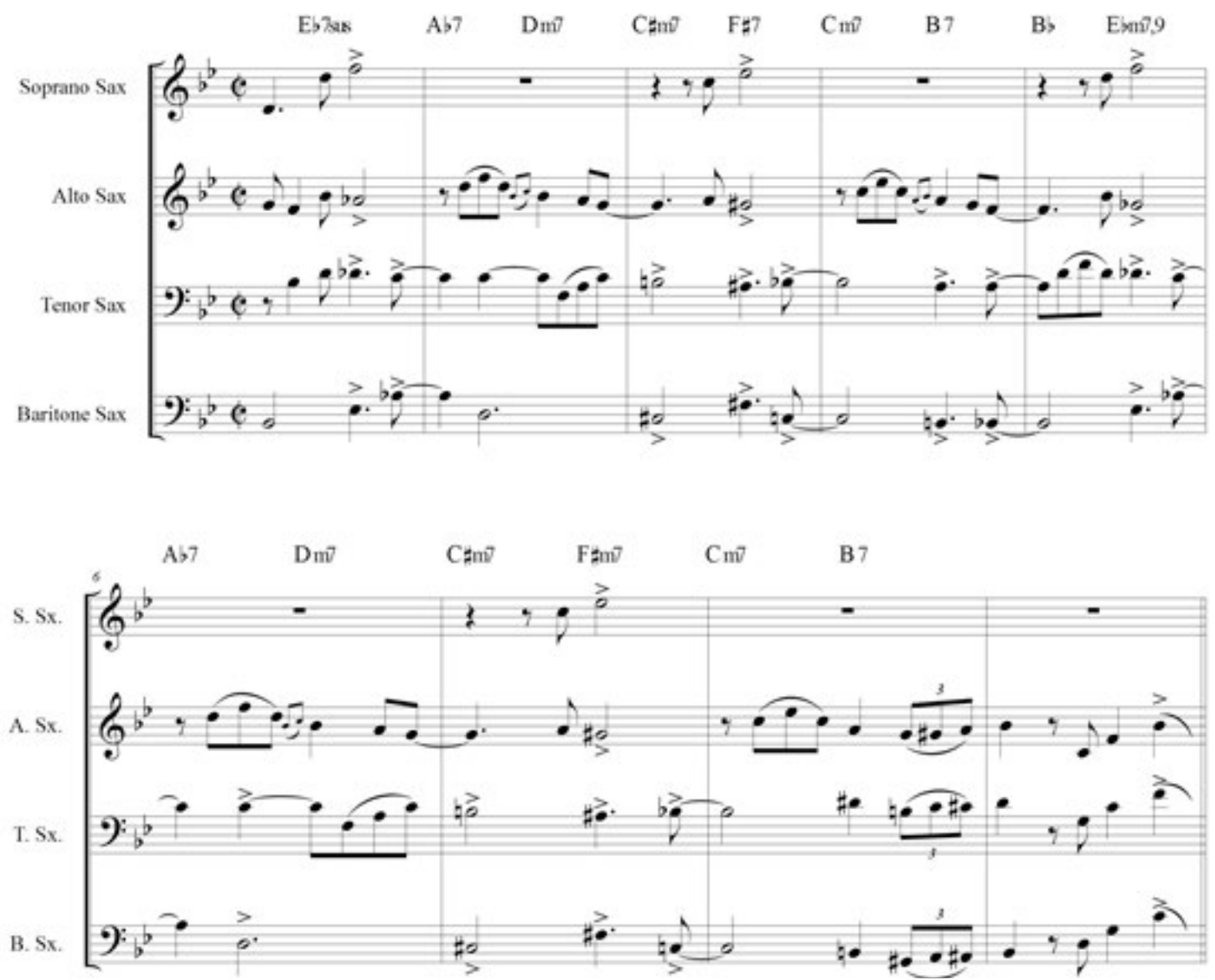

Figura 17. Resoluciones de las las notas guias de los acordes determinadas por el movimiento de quinta del bajo, en el porro La Lorenza (Tradicionald del Sinú)

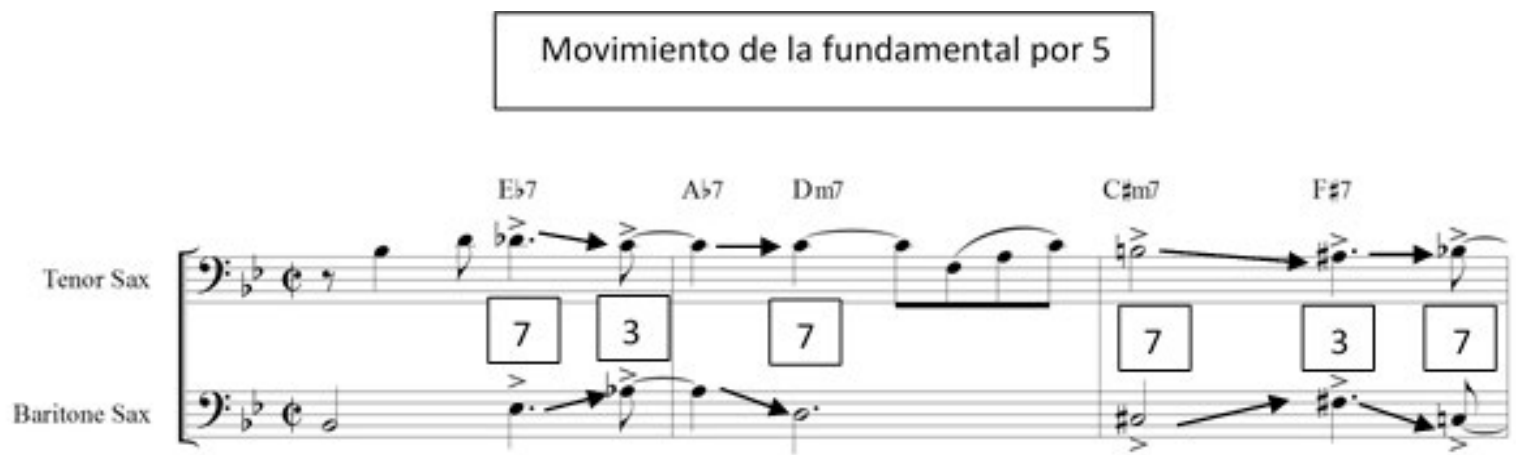

Figura 18. Ilustración detallada de las resoluciones de las las notas guías de los acordes determinadas por el movimiento de quinta del bajo, en el porro La Lorenza 
En el siguiente ejemplo, Roberto Ruiz (Porro de: Antolín Lenes, 1924-1976), se ejemplifica el movimiento de las notas guías cuando el movimiento del bajo es distinto al movimiento de quinta.

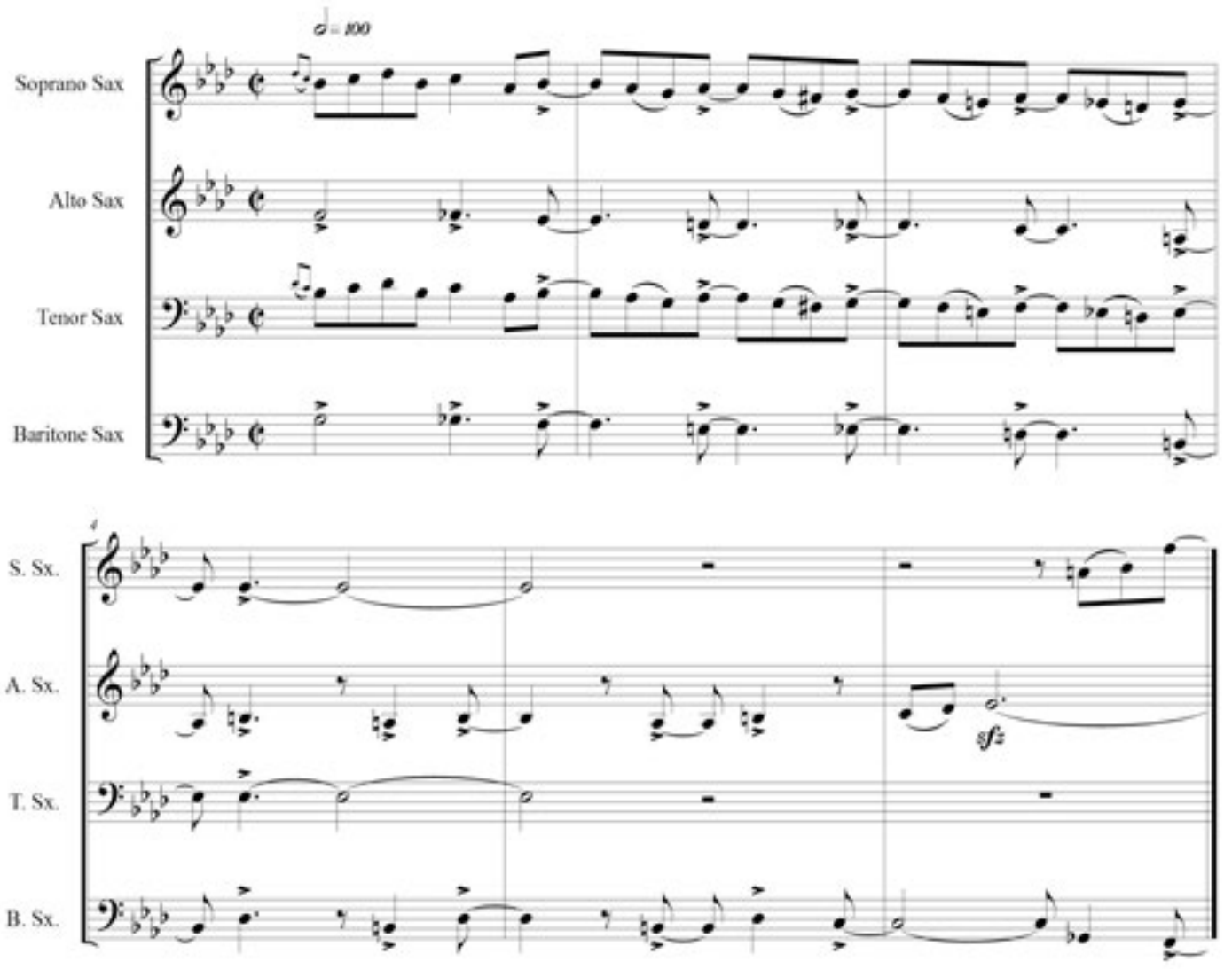

Figura 19. Utilización de las resoluciones de las las notas guías de los acordes determinadas por el movimiento, distinto al de quinta, del bajo

\section{Movimiento de la fundamental distinta al intervalo 5}

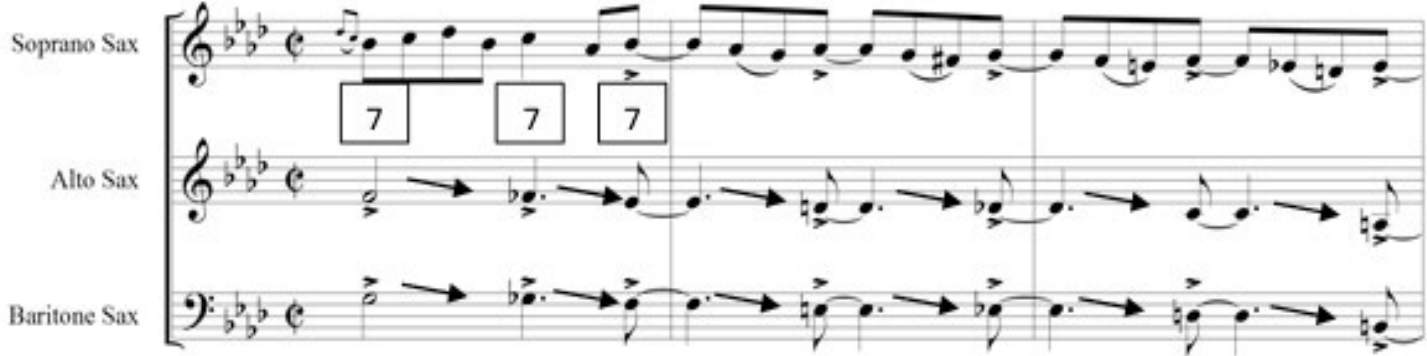

Figura 20. Ilustración detallada de las resoluciones de las las notas guias de los acordes determinadas por el movimiento, distinto al de quinta, del bajo 
b Técnicas de re-armonización: las técnicas de rearmonización son herramientas que proveen de nuevas sonoridades a una progresión armónica existente, ofreciéndole al compositor o arreglista variadas posibilidades de expresar con creatividad una idea musical original.

Una de estas técnicas es la aproximación diatónica. La característica principal de esta técnica es la de darle diversidad al ritmo armónico sin perder el color original de la tonalidad. Su principio es utilizar, exclusivamente, los sonidos diatónicos, de allí su nombre. En el ejemplo citado, la melodía interpretada por el saxofón tenor es tomada como la séptima de cada uno de los acordes que conforman la secuencia.
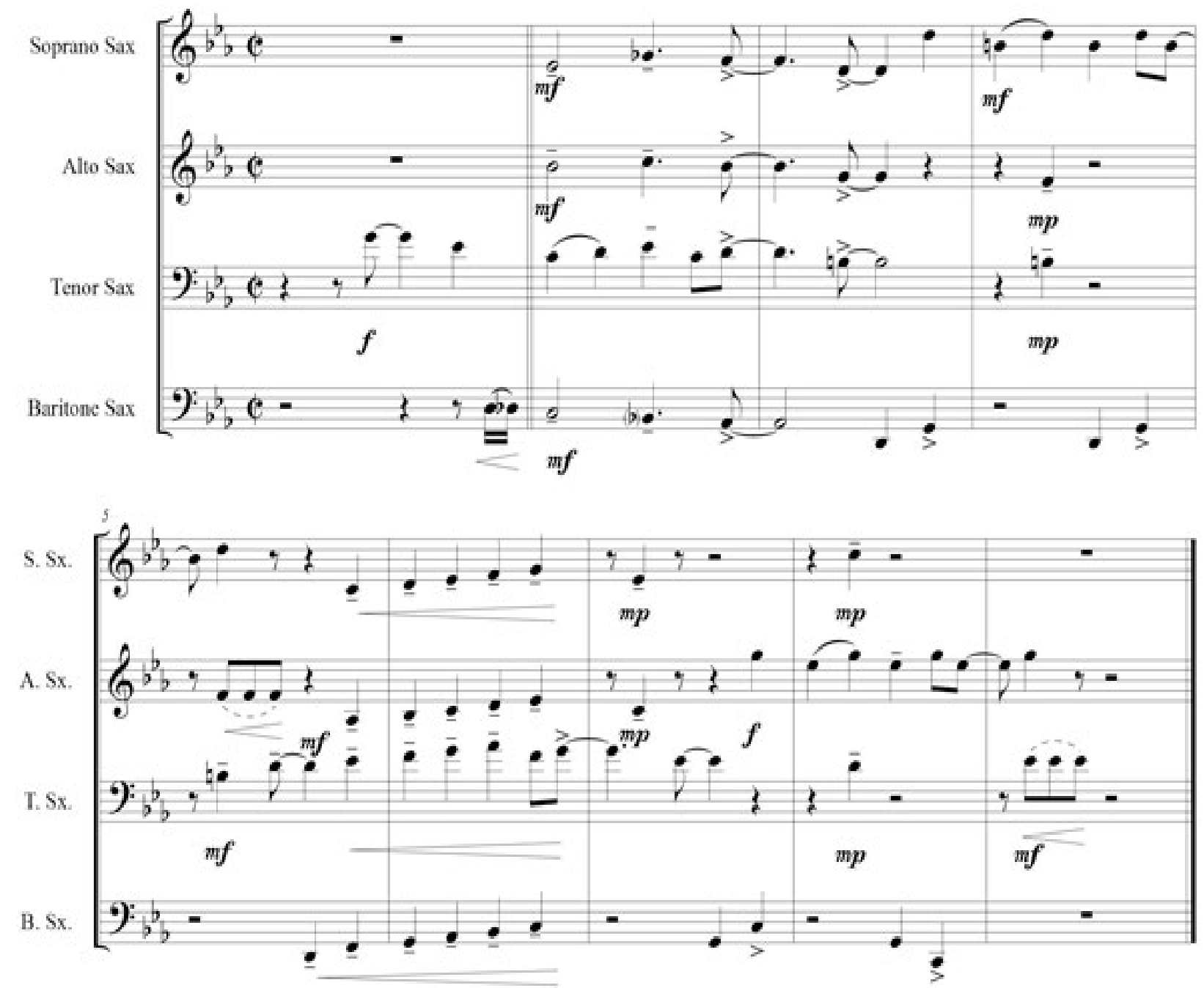

Figura 21. Utilización de la Aproximación diatónica en el Porro Fiesta en corraleja de: Rubén Darío Salcedo (1939) 


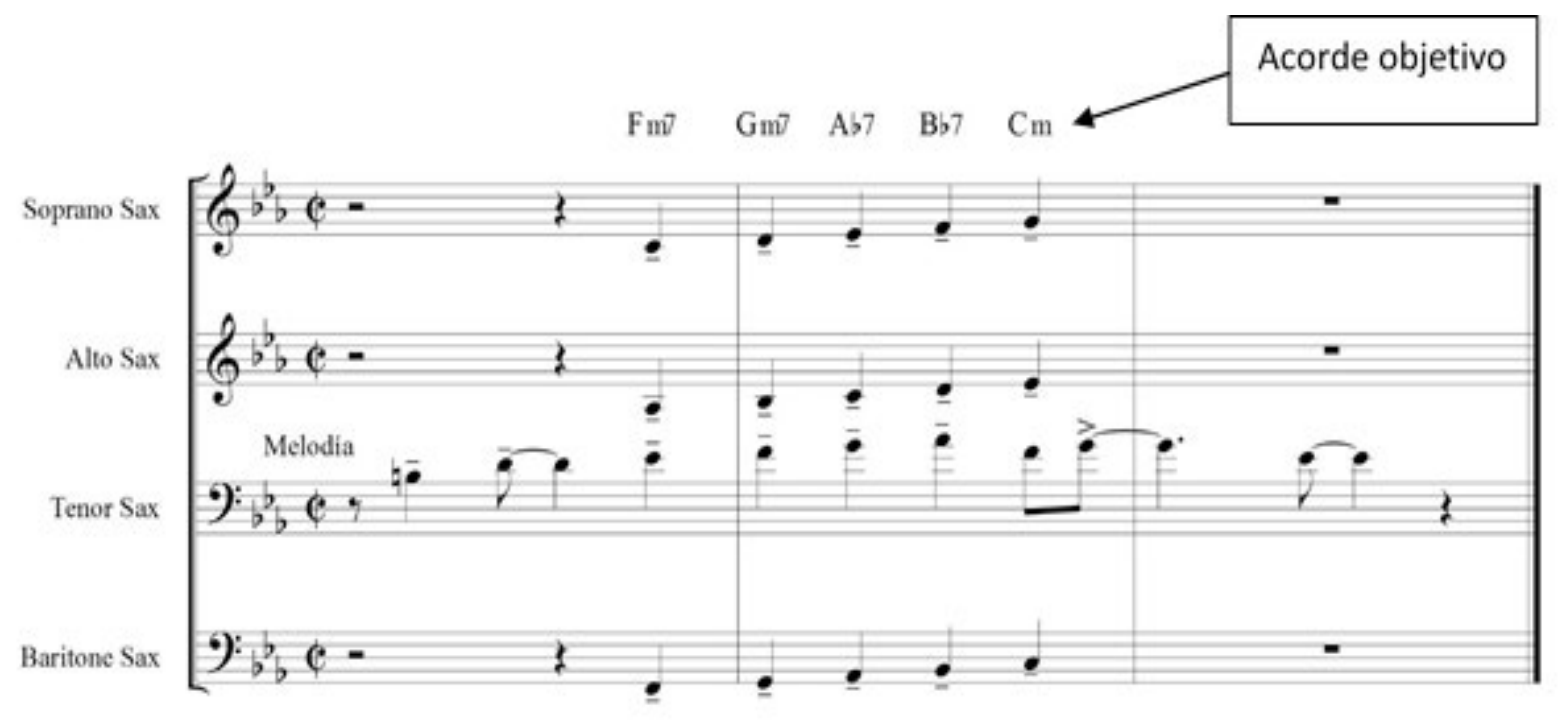

Figura 22. Ilustración detallada de la Aproximación diatónica en el Porro Fiesta en corraleja

Otra técnica es el uso de dominantes extendidas y sustitución tritonal. Esta técnica consiste en una sucesión de acordes de dominante en una frase musical cuyas fundamentales se encadenan por movimiento de quintas justas o segunda menor descendente. Los ejemplos aquí citados son extraídos del arreglo del paseo Roque Guzmán de: Luis Felipe Herrán Lenes (1919-2002), en el cual se tomó como acorde objetivo el Gb7 para que, a partir de este, se origine la secuencia. Como estrategia, se recomienda trabajar de manera retrograda, como se ilustra a continuación:

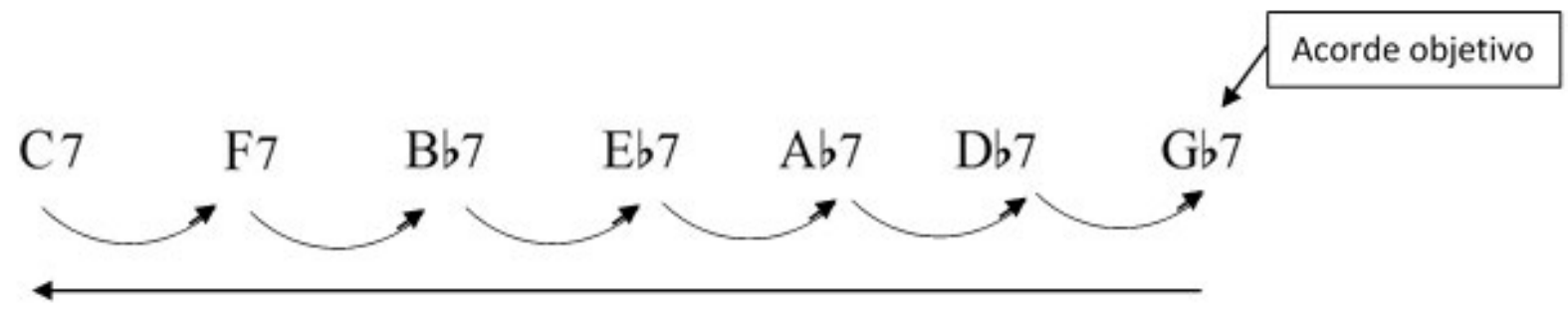

Figura 23. Secuencia de Dominantes extendidas fijando un acorde objetivo

Sin embargo, por la relación existente entre la melodía y la armonía esta versión puede arrojar una segunda propuesta que cambia significativamente el color de la cadencia por medio de la sustitución tritonal. Esta técnica consiste en reemplazar el acorde de dominante original por otra que se encuentra a distancia de cuarta aumentada o quinta disminuida: 


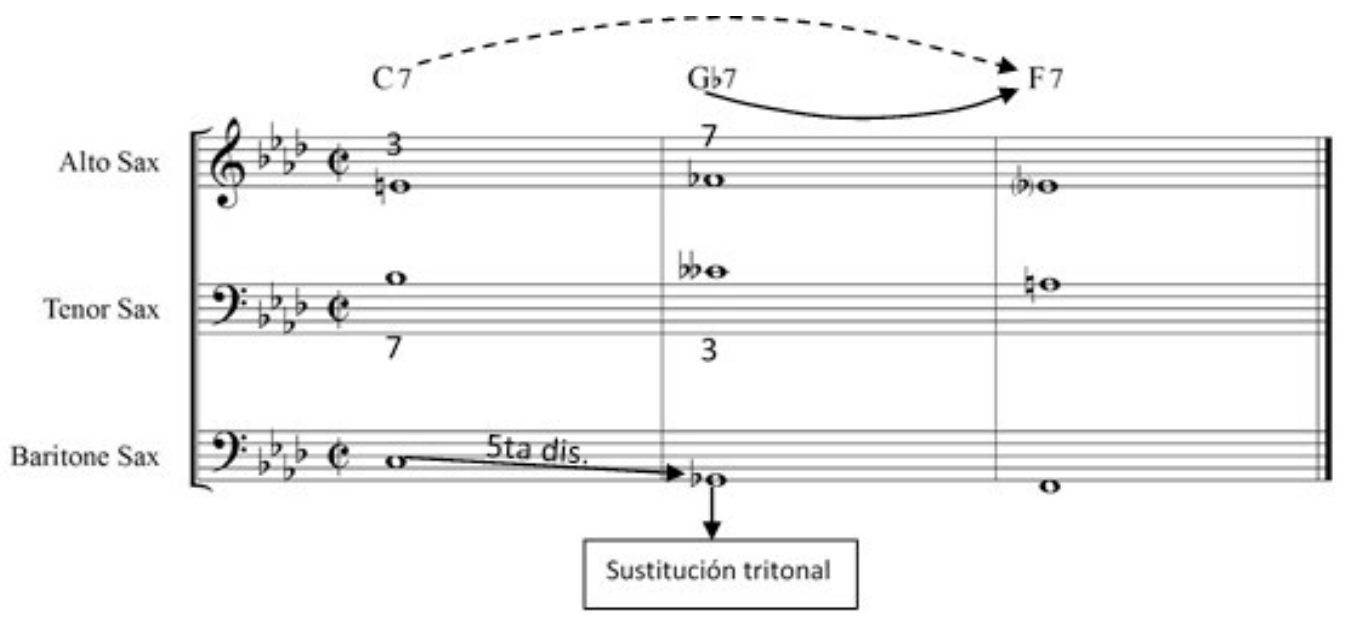

Figura 24. Sustitución de un acorde de dominante por otra ubicada a una quinta disminuida.

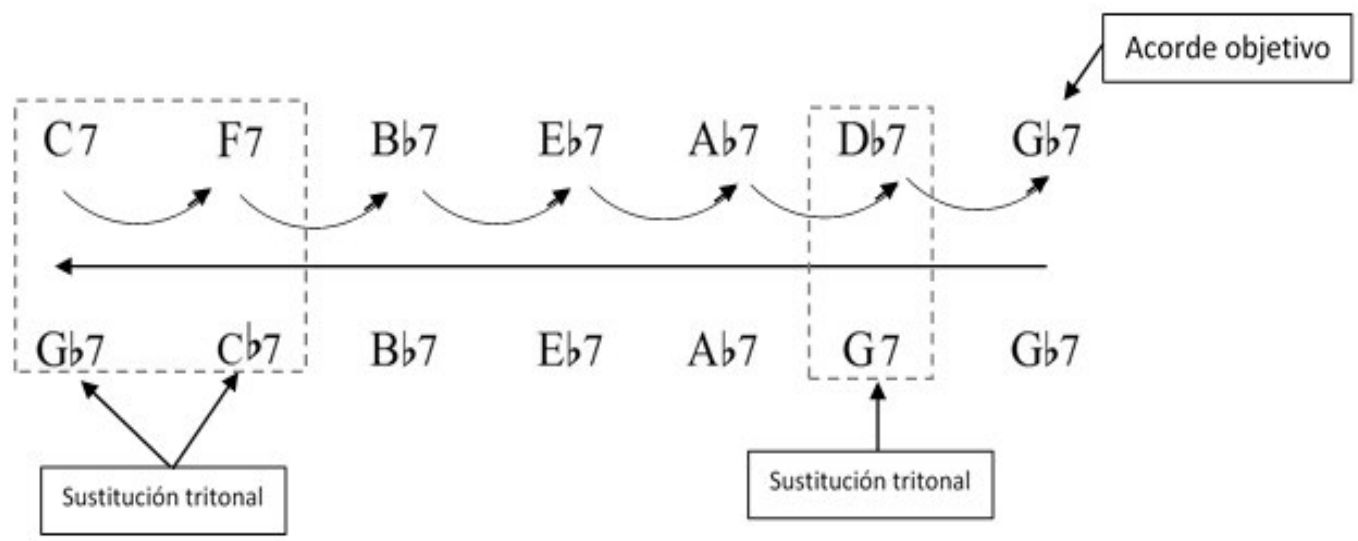

Figura 25. Sustitución tritonal aplicada a la secuencia de la Figura 22

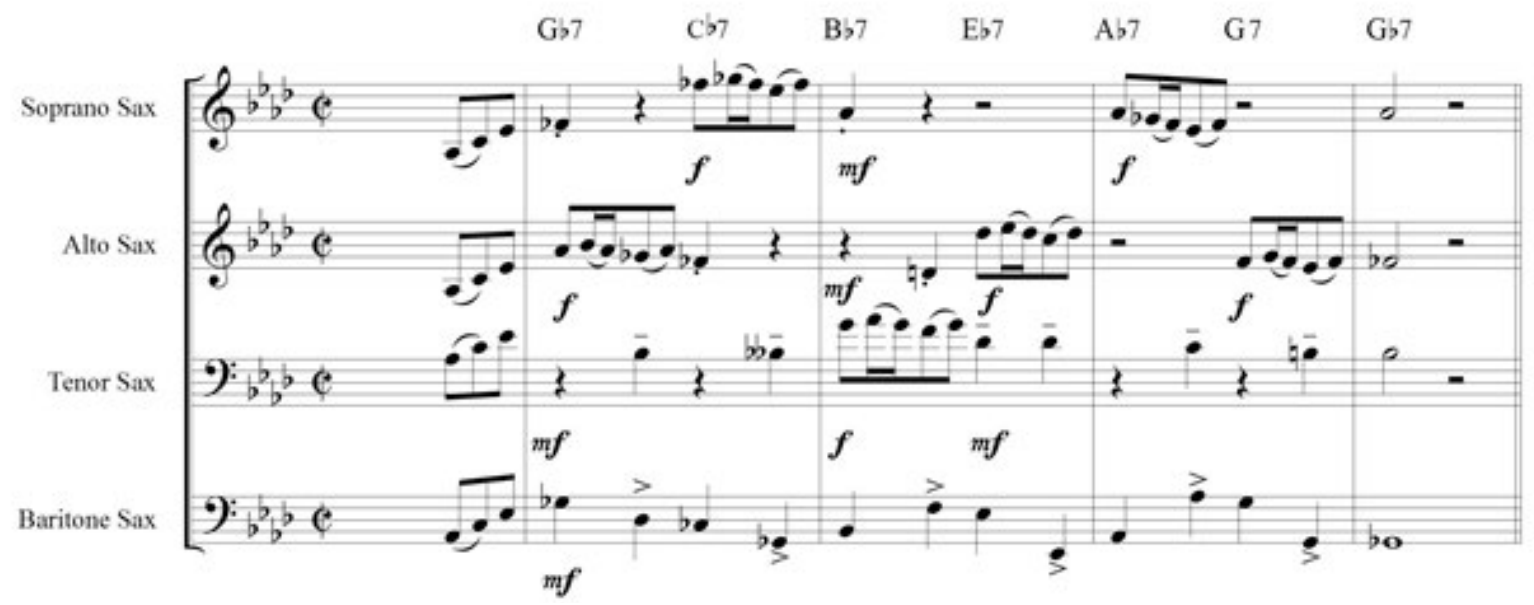

Figura 26. Ejemplo de la utilización de la técnica de Dominantes extendidas y sustitución tritonal. Roque Guzmán (Paseo) 
La línea de bajo es otra técnica utilizada. Consiste en crear una melodía en el bajo, estrechamente relacionada con la melodía principal, basada en grados conjuntos y con una direccionalidad ascendente o descendente. Cada sonido de esta línea podrá ser considerado como la fundamental (F) tercera (3) quinta (5) o séptima (7) de un acorde; distinto a lo que sucede en la aproximación diatónica. En la línea de bajo pueden aparecer sonidos ajenos a la tonalidad, principalmente, sonidos cromáticos (Sustitución tritonal):

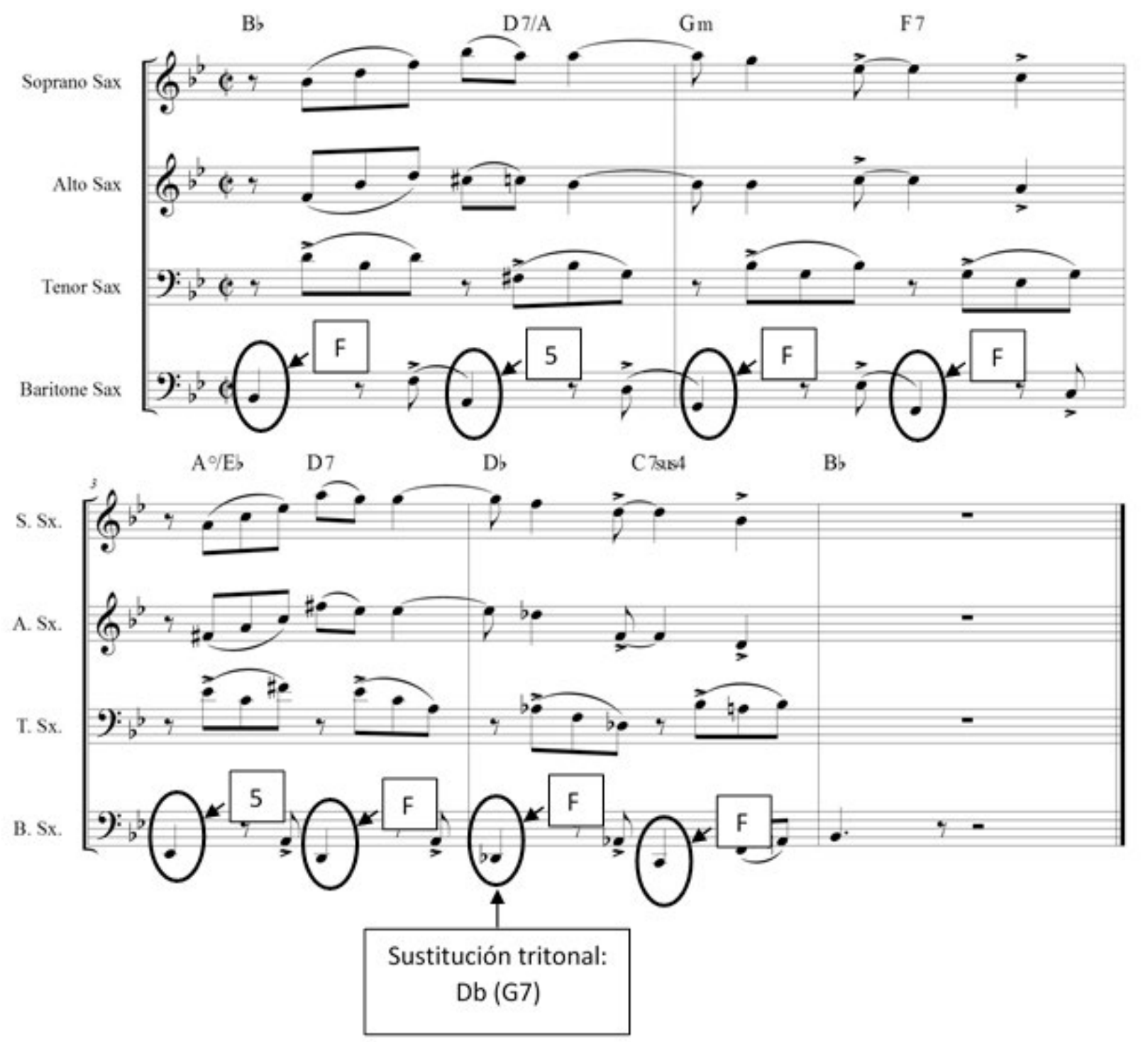

Figura 27. Ejemplo de la utilización de la técnica de Linea de bajo en el fragmento de La Lorenza (DRA)

Otra técnica es el patrón de estructuras constantes. Este es una secuencia, ascendente o descendente, en la cual todos los acordes tienen igual cualidad. Su fuerza sonora consiste en el desplazamiento, ya que lo hace con el sonido del bajo en la fundamental. Estos patrones pueden incluir secuencias de acordes de XMaj7; X7; Xm7 o X7sus4, lo que implica la utilización de sonidos no diatónicos a la tonalidad y estos, con frecuencia, determinan el uso de acordes no funcionales. 


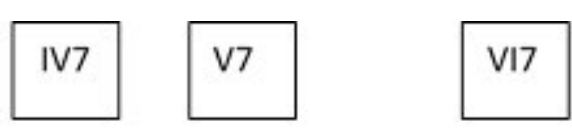

D)7 $\quad$ Eb7 $\quad$ F7

Eb7

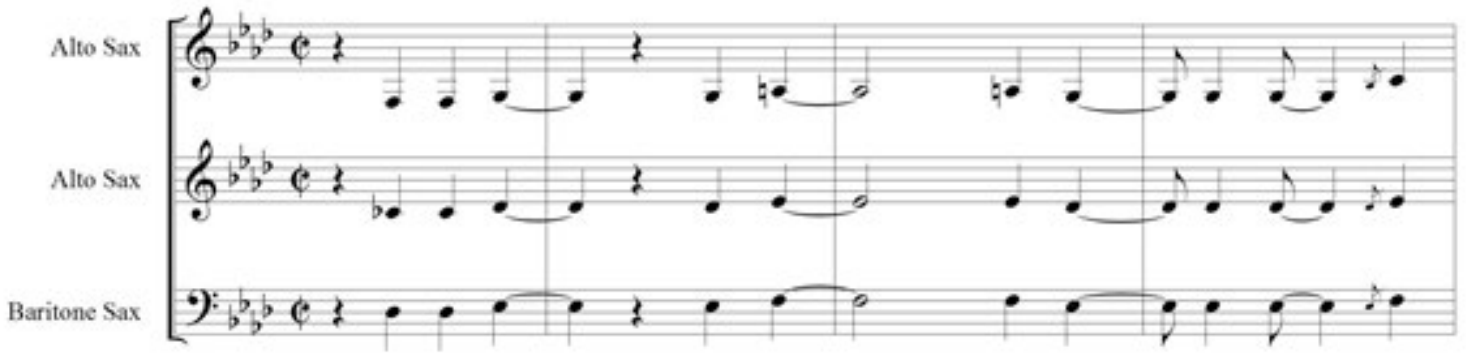

Desplazamiento de los acordes con la fundamental en el bajo

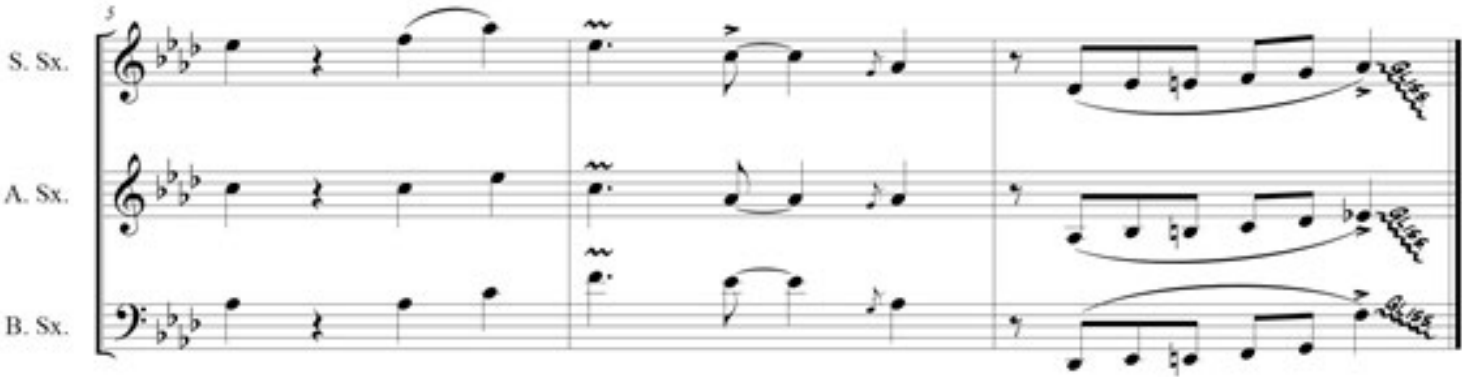

Figura 28. Ejemplo de la utilización del Patrón de estructuras constantes en el fragmento de El sapo (Lambraño, 1978)

Otro de los recursos importantes utilizado en la creación de los arreglos es basar su funcionamiento en la asignación de "Roles" a los saxofones. Este término hace referencia al papel que cada uno de los saxofones juega en un determinado momento de la obra. Con esto se busca variedad y expectativa en su desarrollo, evitando la fatiga tanto del oyente como del intérprete. Hemos considerado relevante citar los roles de: 
Castillo

Melodía en Bloque (Octavas, unísono y voces con igual ritmo),
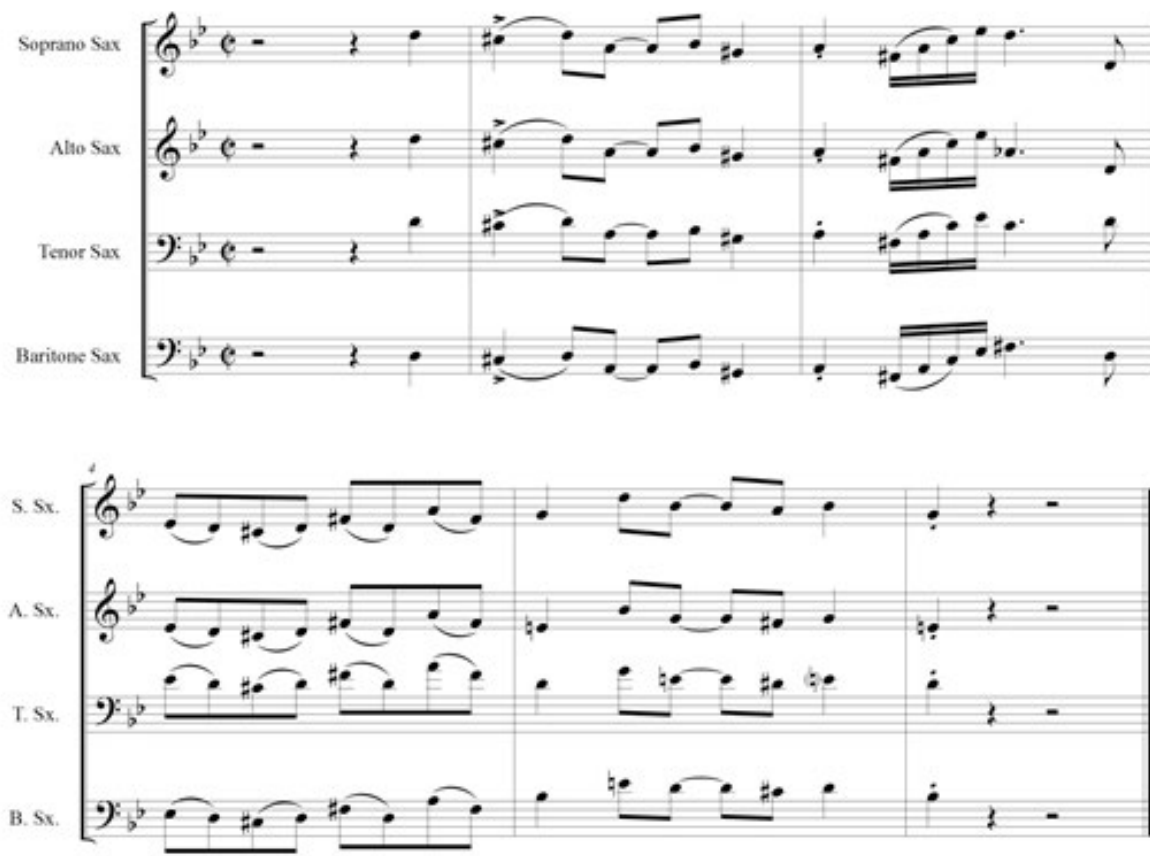

Figura 29. Melodía en bloques: unísono, octavas y voces con igual ritmo. Plaza vieja (Castillo, 2009)

Melodía acompañada de tres acompañantes de igual ritmo,
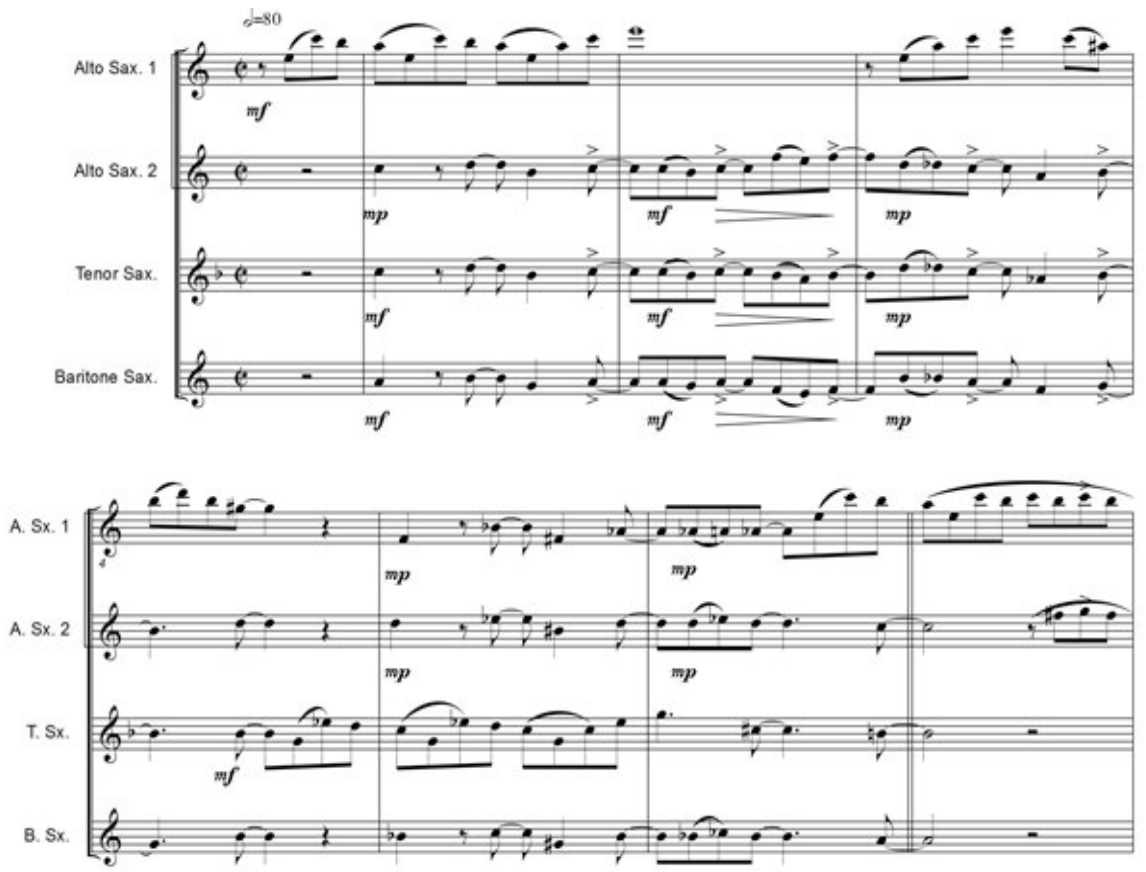

Figura 30. Melodía con tres acompañantes con igual ritmo. Los sabores del porro (Porro) Autor: Pablo Flórez Camargo (1926-2011) 
Melodía con tres acompañantes con diferentes ritmos,

A

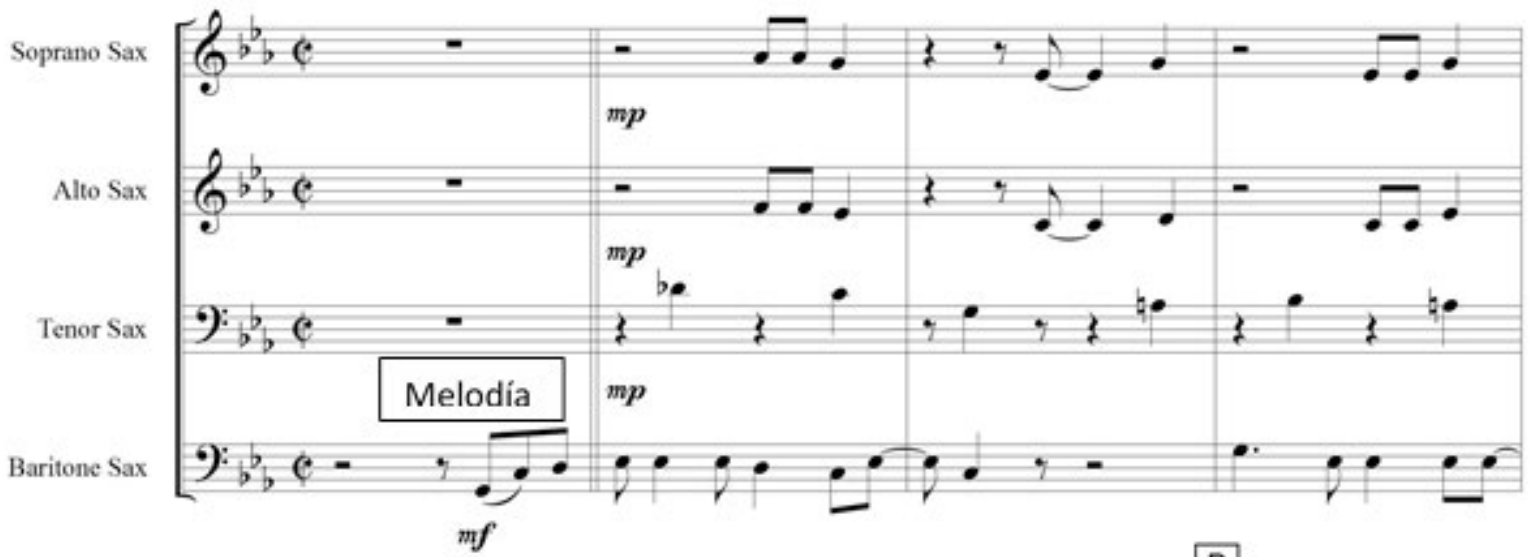

B

S. Sx.

A. Sx.

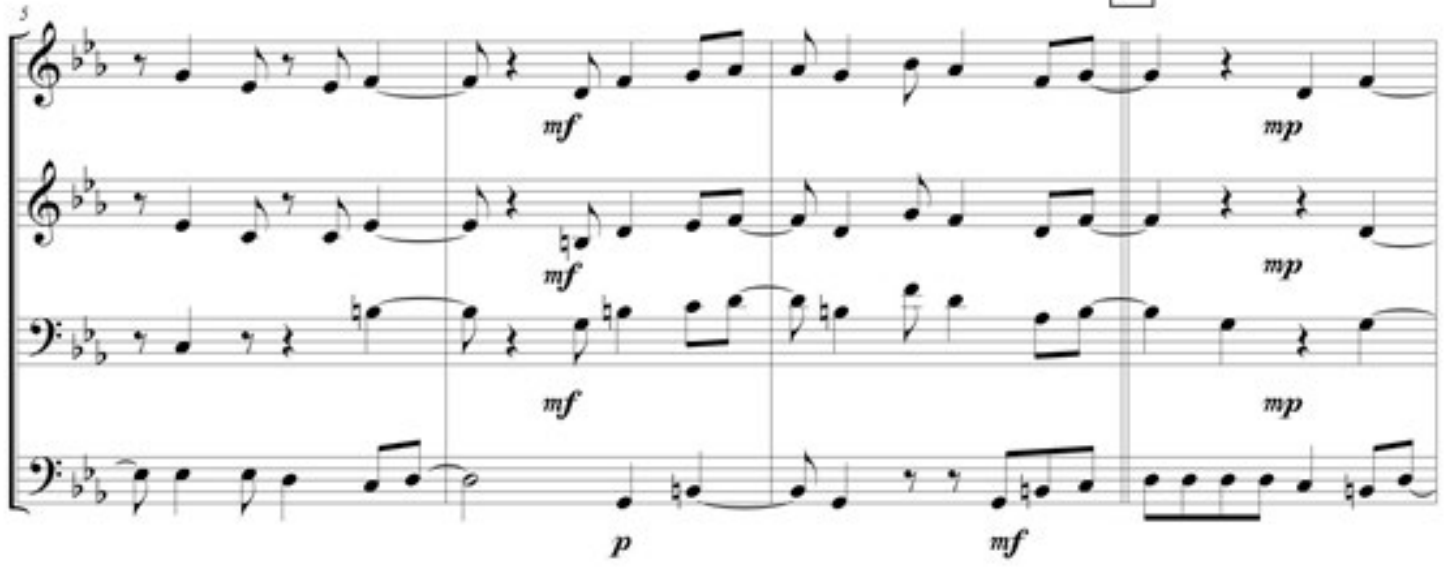

S. Sx.

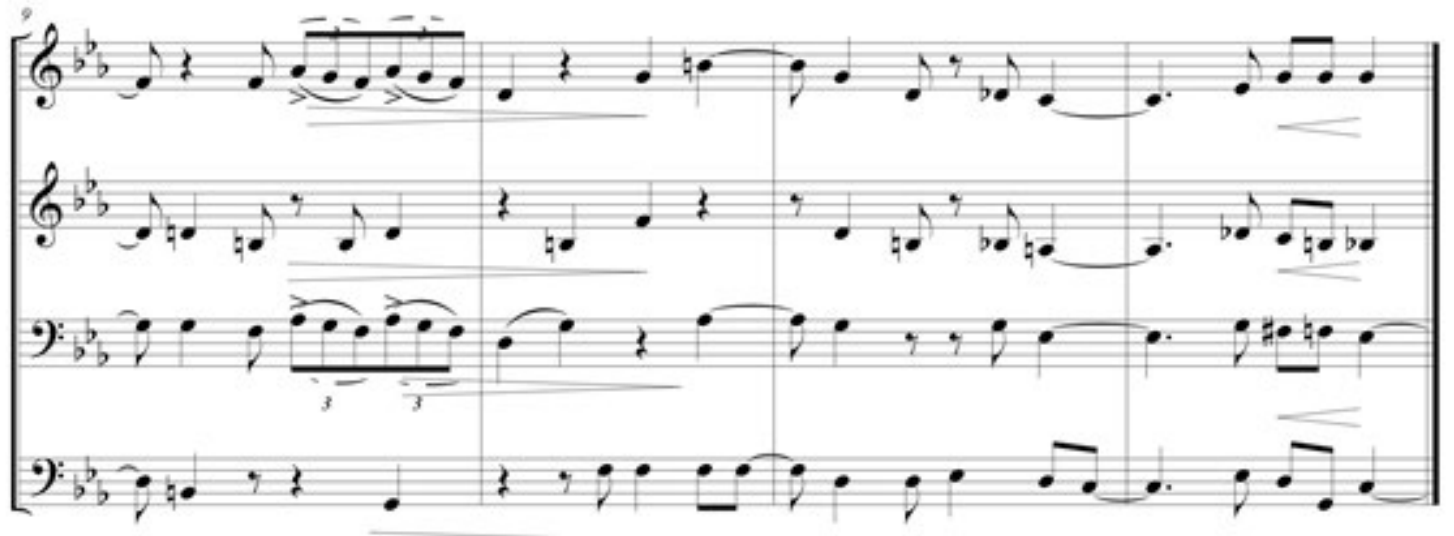

Figura 31. Melodía con tres acompañantes con diferente ritmo. Los sabores del porro 
Melodía a dos voces y dos acompañamientos rítmicos distintos,
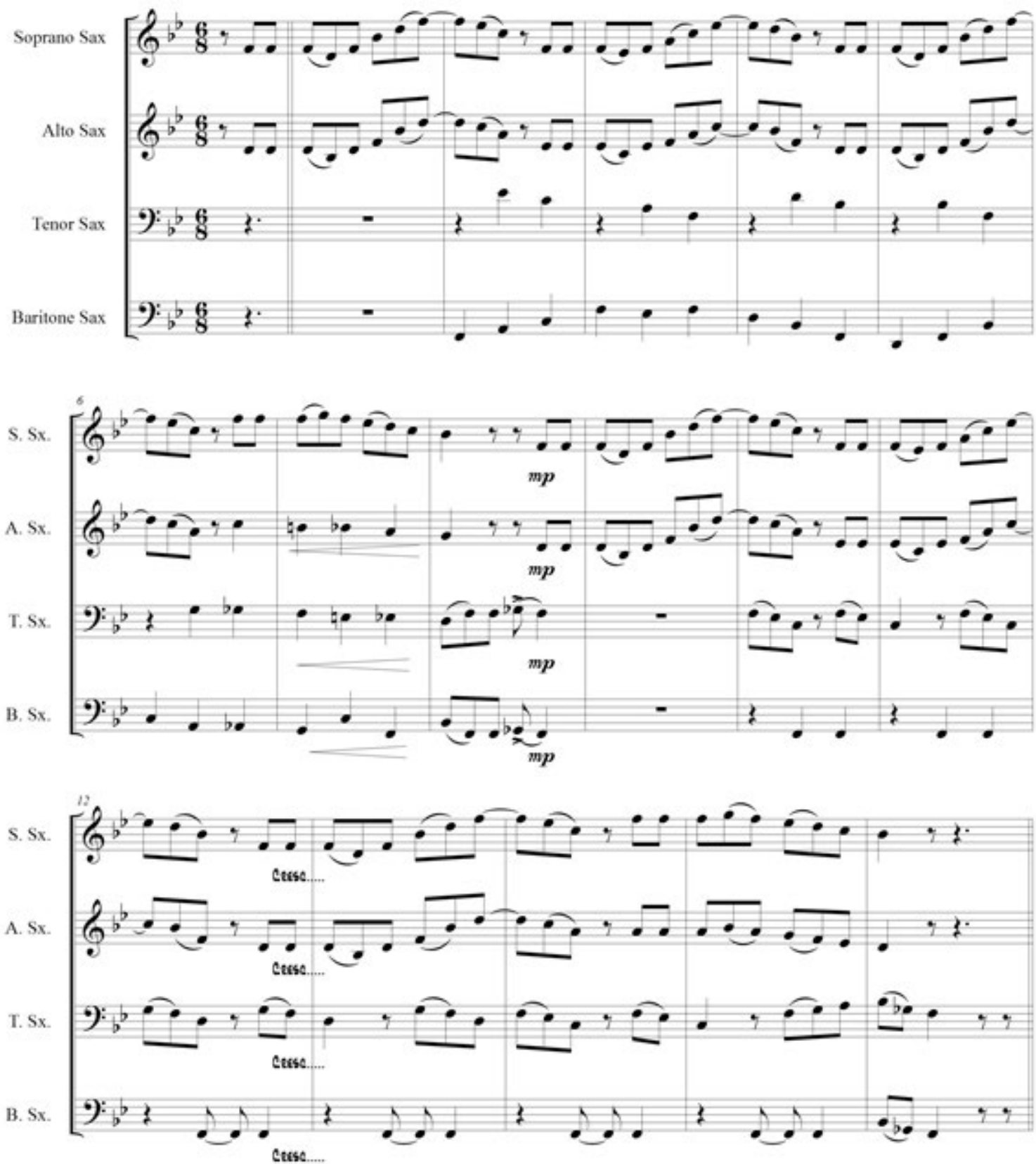

Figura 32. Melodía a dos voces y dos acompañamientos ritmicos distintos. Ron blanco (Fandango) Autor: Pedro Salcedo (1910-1998) 
Melodía y tres acompañantes con ritmo independiente (Mambo),
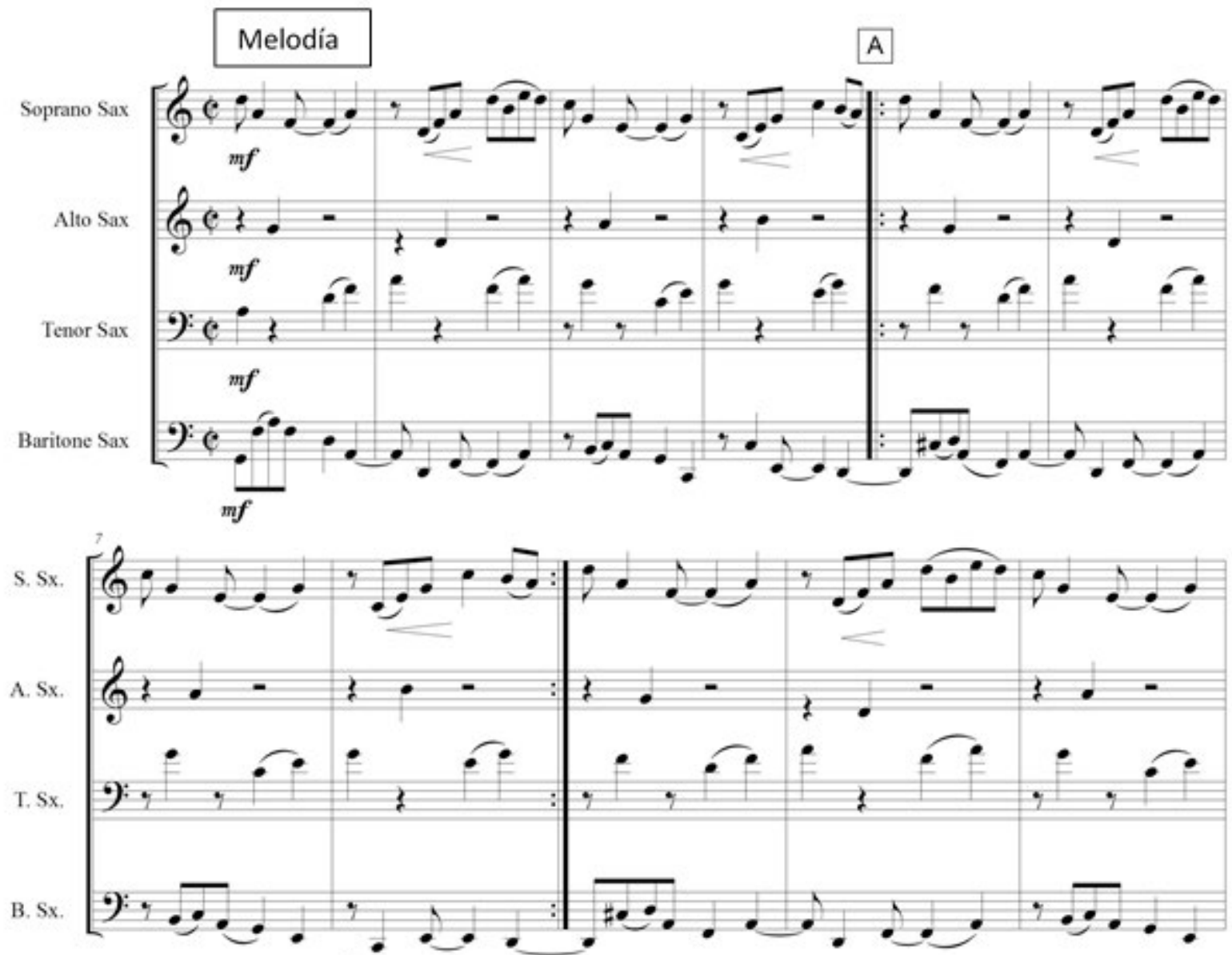

B

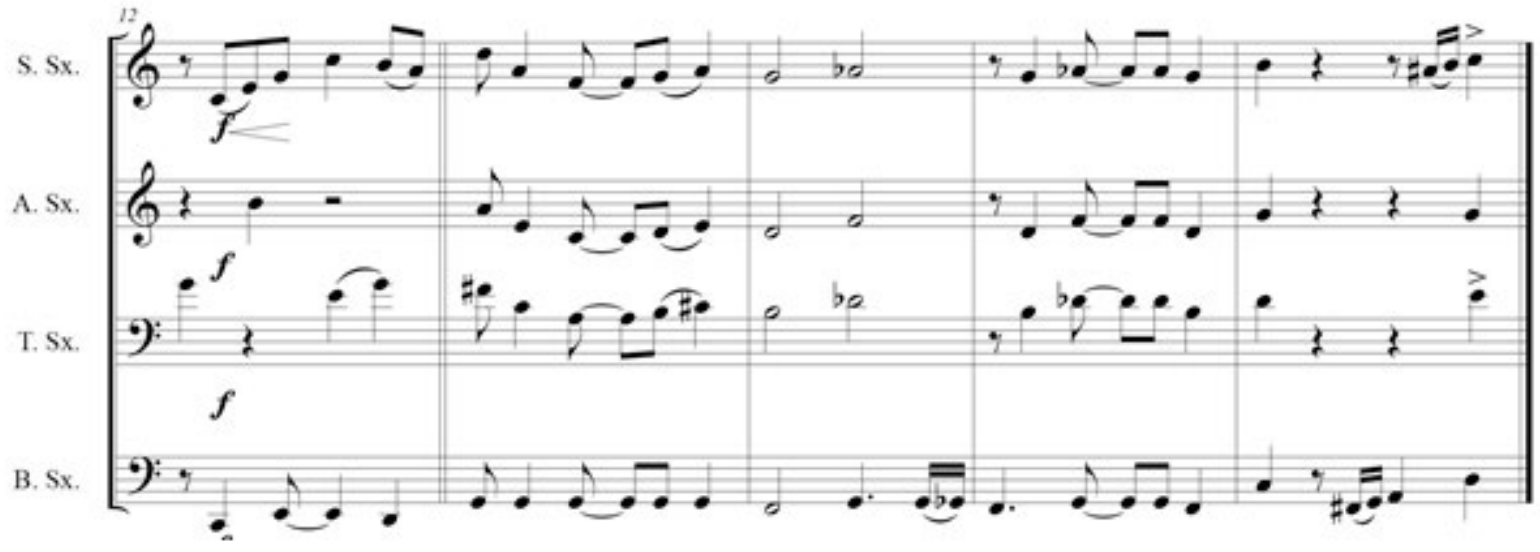

Figura 33. Melodía y tres acompañantes con ritmo independiente (Mambo). Tributo a Panaguá, Autor: Julio Castillo (1969) 


\section{Conclusiones}

Si bien es cierto que existen técnicas que apoyan la creación musical, es innegable que se necesita de la apropiación de los elementos particulares que conforman las músicas regionales con las cuales se pretende trabajar. Este aspecto se podría lograr, preferiblemente, con la inmersión por un período de tiempo prudente en las comunidades de donde son originarias dichas músicas. Alternativamente, se prende lograr a través del entendimiento de sus lógicas por medio de referentes audiovisuales fidedignos.

El proceso creativo está compuesto por un alto porcentaje de subjetivismo, lo cual implica una visión muy particular de la manera como el autor encausa su obra. Por consiguiente, el resultado de este ejercicio musical estará bajo cuestionamientos y críticas de un público que maneja sus propios parámetros estéticos.

Para finalizar, consideramos que con la aplicación de estos materiales se logra la valoración y difusión de la cultura musical regional, por ser este el insumo para la consolidación de una identidad nacional y la afirmación de las bases de un proceso académico basado en las músicas tradicionales.

\section{Bibliografía}

Felts, R. (2002). Reharmonization techniques. Boston: Berklee press.

Pease, T. (s.f.). Jazz composition: Theory and practice. Boston: Berklee press.

Gates, J. (2015). Arranging for horns. Boston: Berklee press.

Mulholland, J. (2013). The Berklee Book of jazz harmony. Boston: Berklee press.

Pullig, K. (2001). Modern Jazz Voicings: Arranging for Small and Medium Ensembles. Boston: Berklee press.

DeGreg, P. (1994). jazz Keyboard harmony. New Albany: Jamey Aebersold jazz inc.

Wade, P. (2002). Música, raza y nación. Chicago: The University of Chicago press.

Delamont, G. (1976). Modern melodic technique. New York: Kendor music, inc.

Alchourron, R. (2007). Composición y arreglos de música popular. Buenos Aires: Melos ediciones musicales.

Valencia, V. (2004). pitos y tambores, cartilla de iniciación musical. Bogotá: Ministerio de cultura.

Castillo, J. (2016). Nuestra música uiversal volumen 4. Montería: Editorial zenú.

Castillo, J. (2010). Nuestra música universal volumen 1. Montería: Fonde editorial de la Universidad de Córdoba.

Castillo, J. (2013). Nuestra música universal volumen 2. Montería: Editorial Zenú.

Castillo, J. (2015). Nuestra música universal volumen 3. Montería: Editorial zení.

Amador, A. (1997). Cultura del porro. Barcelona: Labor.

Aévalo, J. M. (2004). Revista de estudios extremeños. Obtenido de http://sgpwe.izt.uam.mx/files/ users/uami/mcheca/GEOPATRIMONIO/LECTURA2E.pdf

Bermúdez, L. (1980). [Grabado por L. Bermúdez]. De Lucho Bermúdez-50 años de Música [LP]. Daro internacional.

Laguneta-Córdoba, B. 1. (1987). Río Sinú [Grabado por Banda 19 de marzo de Laguneta]. De Río Sinú [Vynilo].

Barros, J. B. (1969). La piragua [Grabado por Los Blacks stars]. De La piragua y otros éxitos bailables [Vinyl]. Colombia.

Sinú, T. d. (1983). La mala palabra [Grabado por Juan Piña]. De Piña para todos [Vinyl].

Lenes, A. (1963). Roberto Ruiz [Grabado por La Sonora Cordobesa]. De Linda Cordobesa [Vinyl].

García, E. (1961). San Carlos [Grabado por La Sonora Cordobesa]. De Gaita del 61 [Vinyl]. Discos 
Fuentes.

Salcedo, R. D. (1969). Fiesta en corraleja [Grabado por Alfredo Gutierrez y los Caporales del Magdalena]. De El disco del año.

Vernia, A. (06 de 2014). Repositori Universitat Jaume I. Obtenido de http://hdl.handle.net/10234/153011

Herrán, L. F. (1989). Roque Guzmán [Grabado por Lizandro Meza y su conjunto]. De Lisandro Mezcladito volumen 3 [Vinyl].

Castillo, J. (2006). Sinú sax quartet [Grabado por Sinú sax quartet]. [CD]. De Julio Castillo y Sinú sax quartet [CD].

Castillo, J. (2008). Plaza vieja [Grabado por Sinú sax quartet]. De Tradición [CD].

Lambraño, G. (1978). El sapo [Grabado por Pacho Galán y su Orquesta]. De Pacho Galán Congo de oro 1977 [Vinyl].

Camargo, P. F. (2003). Los sabores del Porro [Grabado por T. 1. Momposina]. De Evolucion: 20 Anos De Totó La Momposina (Antología 1983-2003) [CD].

Oviedo, J. M. (1960). Tres puntá [Grabado por La Sonora Cienaguera]. De La Sonora Cienaguera [Vinyl].

DRA (1999). La Lorenza [Grabado por Juancho Torres y su Orquesta]. De Y el Verbo se hizo Porro [CD].

Salcedo, P. (1999). Ron Blanco [Grabado por Juancho Torres y su Orquesta]. De Y el Verbo se hizo Porro [CD].

Flórez, P. (1994). Los sabores del porro [Grabado por Juancho torres y su orquesta]. De Los sabores del porro y algo más [CD]. 